\title{
Relação entre o comportamento reológico e a dinâmica do congelamento e descongelamento de polpa de morango adicionada de sacarose e pectina
}

\author{
Relationship between the rheologic behavior and freezing and thawing \\ dynamics of strawberry pulp adding sucrose and pectin
}

\author{
Tatiana Nunes FERNANDES ${ }^{1}$, Jaime Vilela RESENDE ${ }^{1 *}$, Rafael Souza Ribeiro CRUVINEL ${ }^{1}$, Marciu José RENO
}

\section{Resumo}

Polpas de morango (Fragaria ananassa) adicionadas de sacarose $(0 ; 2,91 ; 10,0 ; 17,09 ; 20 \%$ peso/peso) e pectina $(0 ; 0,15 ; 0,50 ; 0,85$ e $1,0 \%$ peso/peso) foram caracterizadas quanto às propriedades físico-químicas e reológicas. As relações entre o comportamento reológico, as dinâmicas de congelamento/descongelamento e microestrutura dos cristais de gelo foram estabelecidas. Caracterizações físico-químicas e reológicas das amostras foram feitas antes e depois do congelamento/descongelamento. O congelamento foi realizado em banho ultratermostático a $-20^{\circ} \mathrm{C}$ em cilindro de aço inoxidável com isolamento térmico no fundo, assegurando congelamento unidimensional. A fração de gelo nas amostras foi calculada usando modelos teóricos e durante o congelamento foi avaliada a concentração polarizada das amostras a cada 60 minutos. O descongelamento foi avaliado a $19^{\circ} \mathrm{C}$ pela relação tempo $\mathrm{x}$ aumento de área sendo estas obtidas por edição de fotografias e quantificadas em software analisador de imagens. As polpas apresentaram comportamento de fluido pseudoplástico e foi verificado um efeito sinergístico da sacarose e pectina em meio ácido observado pela variação da viscosidade. Os descongelamentos foram mais rápidos nas amostras mais concentradas de sacarose e pectina. Análises microestruturais mostraram que a adição de sacarose e pectina aumenta a velocidade da frente de congelamento nas amostras mais concentradas.

Palavras-chave: reologia; polpa de fruta congelada; microestrutura; sacarose; pectina.

\begin{abstract}
The physicochemical and rheological properties of strawberry (Fragaria ananassa) pulps with the addition of sucrose $(0 ; 2.91 ; 10.0 ; 17.09 ; 20 \%$ weight/weight) and pectin $(0 ; 0.15 ; 0.50 ; 0.85 ; 10 \%$ weight/ weight) were characterized. The relationship in rheology, freezing and thawing dynamics and the ice crystal microstructures were established. The characterizations were performed before and after the freezing/thawing process. The samples were frozen in a water-bath at $-20^{\circ} \mathrm{C}$, in a stainless steel recipient with a thermal insulation at the bottom to establish the radial heat flow in an infinite cylinder. The ice fractions were calculated using mathematical equations and the polarized concentrations were evaluated at every 60 minutes. The thawing process was assessed by the relationship between time and surface area growing with the thawing process at $19^{\circ} \mathrm{C}$. The strawberry pulp was a pseudoplastic fluid. The pulps showed a sucrose and pectin synergic effect in acid environment and this fact confirmed the variation in the viscosity, thawing rate and freezing front velocity. The thawing process of the strawberries was faster for the higher concentrated samples. The microstructure of strawberry pulps was influenced by the factors studied, increasing the freezing front velocity on the most concentrated samples.

Keywords: rheology; frozen fruit pulp; microstructure; sucrose; pectin.
\end{abstract}

\section{Introdução}

No Brasil a maior parte da produção de alimentos é sazonal, principalmente a de origem vegetal, e o desenvolvimento de métodos essenciais que prolonguem o período de armazenamento se faz necessário. O Brasil é um dos maiores produtores em vários mercados de frutas, sendo notável a grande variedade destes itens no mercado.

O processamento de polpa de frutas para obtenção de polpas congeladas é uma atividade agroindustrial importante na medida em que se agrega valor econômico à fruta. A conservação de frutas na forma de sucos, de polpas congeladas e de outros produtos foi desenvolvida para aumentar sua oferta e para a utilização dos excedentes de produção. Sua utilização é quase sempre como matéria-prima para processamento de outros produtos como néctares, sucos, geleias, sorvetes e doces. (BRUNINI; DURIGAN; OLIVEIRA, 2002).

O congelamento é um dos métodos mais eficientes para a manutenção da qualidade de frutas (sucos, polpas, inteiras e em pedaços) diminuindo os efeitos de deterioração quando estes estão expostos à temperatura ambiente. O congelamento, embora eficiente, produz efeitos prejudiciais comprometendo a qualidade dos produtos que depende da velocidade, do meio de resfriamento e das condições de armazenamento posterior (FENNEMA; POWRIE; MARTH, 1973).

Quando a fruta é congelada na forma de polpa, o efeito do processo de congelamento é verificado pela alteração 
na consistência da polpa e através de mudanças em suas composições causadas por reações químicas durante o armazenamento posterior. A consistência da polpa e a aparência global são mais bem mantidas quando a polpa é congelada rapidamente (WANG; CHANG, 1994).

Polpas de frutas com adição de pectina e sacarose têm sido usadas como matéria-prima em diversos processos tais como na fabricação de geleias, doces, sorvetes e picolés. O uso destes aditivos afeta o comportamento reológico da polpa de fruta alterando a concentração de componentes em relação à polpa original e consequentemente as características físico-químicas e microestruturais dos produtos obtidos nas etapas posteriores do processamento como no congelamento e descongelamento.

Ainda existe uma discussão sobre a influência da presença de hidrocoloides na forma dos cristais de gelo, quantidade (água congelável) e sobre o tamanho dos cristais de gelo. Os cristais de gelo podem ser menores ou não, de acordo com a capacidade dos hidrocoloides de se ligarem à água e aumentarem a viscosidade da mistura (FERNÁNDEZ et al., 2007). No substrato ácido da fruta, a pectina é um coloide que contém cargas negativas. A adição de açúcar a esse substrato influencia o equilíbrio entre a pectina e a água, desestabilizando a pectina, formando uma malha semelhante a uma rede capaz de reter líquido e aglutinar o açúcar sob a forma de um gel. A rigidez da malha é também influenciada pela concentração de açúcar e pela acidez do meio. Quanto maior a concentração de açúcar, menor quantidade de água livre será encontrada na estrutura, logo a estrutura será mais rígida (SILVA, 2000).

O processo de congelamento é extremamente dependente das propriedades relacionadas ao produto. $\mathrm{O}$ conhecimento dos fatores que interferem na mudança de estado da polpa é substancial para o monitoramento e controle do cristal de gelo e consequentemente da qualidade do produto congelado (GEORGE, 1993). A incorporação de aditivos em diferentes concentrações na polpa é capaz de modificar o comportamento dinâmico do congelamento e a disposição das moléculas de água no estado cristalino.

Em diferentes sistemas, essas substâncias promovem estruturações específicas (hexagonal, arbórea ou esférica) de grande relevância porque caracterizam as interações nos sistemas polpa-cristal de gelo (CARNEIRO, 2001). Também influenciam nos fenômenos de concentração (separação) por polarização, número e tamanho dos cristais de gelo durante o congelamento e velocidade de escoamento como fluidez durante o descongelamento.

O presente trabalho teve como objetivos: (i) determinar as propriedades químicas, físicas e físico-químicas das polpas de morango com adição de pectina e sacarose em diferentes concentrações e suas alterações devido aos processos de congelamento e descongelamento; (ii) determinar o comportamento reológico das polpas antes do congelamento e depois do descongelamento em função das diferentes concentrações de aditivos; e (iii) avaliar a dinâmica e microestrutura dos sistemas durante o congelamento e descongelamento e correlacionar os resultados com os parâmetros que caracterizam a viscosidade nestes processamentos.

\section{Material e métodos}

\subsection{Preparo das amostras}

Para obtenção das polpas de frutas, morangos (Fragaria ananassa L., cv. Oso Grande) foram higienizados, processados com a utilização de microprocessador (Braun AG 4243) e refinados em peneira (Granutest com abertura de 0,6 $\mathrm{mm}$ ). Foram adicionadas sacarose (ISOFAR) e pectina cítrica (PROQUİMIOS) às polpas, cujas concentrações são mostradas na Tabela 1, e homogeneizadas com o auxílio do misturador Turratec TE-102.

\subsection{Delineamento experimental}

Para estudo dos efeitos da adição de sacarose e pectina nas polpas sobre a variável resposta, utilizou-se o delineamento rotacional composto associado ao método de superfície de resposta (MSR), conforme descreve Rodrigues, Iemma (2005). Foram utilizados 11 tratamentos, sendo quatro pontos fatoriais, três repetições no ponto central e quatro pontos axiais $\left(2^{\mathrm{k}}\right)$ (Tabela 1). Foram estudados os efeitos de duas variáveis independentes: adição de sacarose em porcentagem (X1) e adição de pectina em porcentagem (X2).

\subsection{Análises físico-químicas}

As análises foram realizadas com as polpas de morango sem aditivos e nos 11 tratamentos com adição de sacarose e pectina, antes do congelamento e depois do descongelamento. $\mathrm{O}$ descongelamento foi feito à temperatura ambiente $\left(19^{\circ} \mathrm{C}\right)$.

A determinação de sólidos solúveis foi feita por refratometria segundo o método 932.12 da AOAC (1990) com o uso do refratômetro digital da marca ATAGO PR-100. Os resultados foram expressos em ${ }^{\circ}$ Brix.

A atividade de água (Aw) das amostras foi obtida por leitura direta no termo-higrômetro AQUA-LAB digital, modelo CX-2 (Decagon Devices Inc.) com temperatura controlada de $25,0 \pm 0,5^{\circ} \mathrm{C}$.

Tabela 1. Estrutura dos tratamentos segundo o delineamento rotacional composto para duas variáveis e três níveis

\begin{tabular}{ccccc}
\hline & \multicolumn{2}{c}{ Codificado } & \multicolumn{2}{c}{ Real (\%) } \\
\hline Ensaios & $\begin{array}{c}\text { Adição de } \\
\text { sacarose }\end{array}$ & $\begin{array}{c}\text { Adição de } \\
\text { pectina }\end{array}$ & $\begin{array}{c}\text { Adição de } \\
\text { sacarose }\end{array}$ & $\begin{array}{c}\text { Adição de } \\
\text { pectina }\end{array}$ \\
\hline 1 & -1 & -1 & 2,91 & 0,15 \\
2 & +1 & -1 & 17,09 & 0,15 \\
3 & -1 & +1 & 2,91 & 0,85 \\
4 & +1 & +1 & 17,09 & 0,85 \\
5 & 0 & 0 & 10,00 & 0,50 \\
6 & 0 & 0 & 10,00 & 0,50 \\
7 & 0 & 0 & 10,00 & 0,50 \\
8 & $-1,41$ & 0 & 0,00 & 0,50 \\
9 & $+1,41$ & 0 & 20,00 & 0,50 \\
10 & 0 & $-1,41$ & 10,00 & 0,00 \\
11 & 0 & $+1,41$ & 10,00 & 1,00 \\
\hline
\end{tabular}


A coloração da polpa foi analisada com colorímetro eletrônico Minolta Chroma Meter CR 2000 (Minolta Câmera Co. Ltd) a $25{ }^{\circ} \mathrm{C}$. Neste sistema de representação de cor, os valores $\mathrm{L}^{*}, \mathrm{a}^{*} \mathrm{e} \mathrm{b}^{*}$ descrevem a uniformidade da cor no espaço tridimensional, em que o valor $\mathrm{L}^{\star}$ corresponde a quão claro e quão escuro é o produto analisado (0: preto; 100: branco). Os valores de $\left(\mathrm{a}^{*}\right)$ correspondem à escala do verde ao vermelho ( $a^{*}$ negativo, verde; $\mathrm{a}^{\star}$ positivo, vermelho) e os valores de $\left(\mathrm{b}^{*}\right)$ correspondem à escala do azul ao amarelo ( $\mathrm{b}^{\star}$ negativo, azul; $\mathrm{b}^{\star}$ positivo, amarelo).

A tonalidade $\left(a^{*} / b^{*}\right)$ e a saturação $\left(a^{* 2}+b^{* 2}\right)$ foram calculadas. O cálculo do índice colorimétrico diferença de cor $\left(\Delta \mathrm{E}^{\star}\right)$ foi obtido pela Equação (1) (Minolta, 1994).

$\Delta E^{*}=\left[(\Delta L *)^{2}+(\Delta a *)^{2}+(\Delta b *)^{2}\right]^{0,5}$

em que:

$\Delta \mathrm{E}^{\star}=$ valor para diferença de cor;

$\Delta \mathrm{L}^{*}=$ diferença entre a leitura $\mathrm{L}^{\star}$ da amostra antes de congelar e a leitura $\mathrm{L}^{\star}$ da amostra descongelada;

$\Delta \mathrm{a}^{*}=$ diferença entre a leitura $\mathrm{a}^{*} \mathrm{da}$ amostra antes de congelar e a leitura $\mathrm{a}^{\star}$ da amostra descongelada; $\mathrm{e}$

$\Delta \mathrm{b}^{*}=$ diferença entre a leitura $\mathrm{b}^{*}$ da amostra antes de congelar e a leitura $b^{*}$ da amostra descongelada.

$\mathrm{O} \mathrm{pH}$ foi determinado por potenciometria com eletrodo indicador de vidro, utilizando o pHmetro Schott Handylab.
A acidez titulável foi analisada pelo método de volumetria 942.15 da AOAC (1990). O extrato ( $1 \mathrm{~mL}$ de polpa/50 $\mathrm{mL}$ de água destilada) foi titulado com hidróxido de sódio $(\mathrm{NaOH} 0,1 \mathrm{~N})$, tendo como indicador a fenolftaleína. Os resultados foram expressos em porcentagem de gramas de ácido cítrico por $100 \mathrm{~g}$ de amostra.

A determinação da umidade foi feita por método gravimétrico (secagem em estufa a $105^{\circ} \mathrm{C}$ até peso constante) segundo AOAC (1990).

\subsection{Congelamento}

As polpas foram submetidas ao congelamento por imersão de um recipiente cilíndrico em banho ultratermostático (Nova Ética, modelo $521 / 3 \mathrm{DE}$ ) com temperatura controlada de $-20^{\circ} \mathrm{C}$ e uso de solução $50 \%$ de álcool como líquido refrigerante (CHEVALIER; LEBAIL; GHOUL, 2000). O recipiente cilíndrico foi confeccionado em aço inox com fundo isolado termicamente por uma peça constituída de poliuretano revestido de nylon (Figura 1) para assegurar somente o fluxo de calor radial. A polpa foi adicionada ao recipiente até o nível de $60 \mathrm{~mm}$ (aproximadamente $500 \mathrm{~g}$ de amostra).

Para a obtenção dos históricos de temperatura das amostras foram instalados dois termopares tipo $\mathrm{T}$ (cobre-constantan, 36 AWG, Omega), um no centro geométrico (raio $=0 \mathrm{~mm} \mathrm{e}$ altura $30 \mathrm{~mm}$ ) e o outro na mesma altura, mas na posição de raio igual a $45 \mathrm{~mm}$ do centro (mais próximo da superfície). Os registros das temperaturas foram feitos através de um sistema de aquisição de dados e condicionamento de sinais modular (National Instruments, modelo SCXI) em intervalos de coleta de 2 minutos por 3 horas (Figura 1).

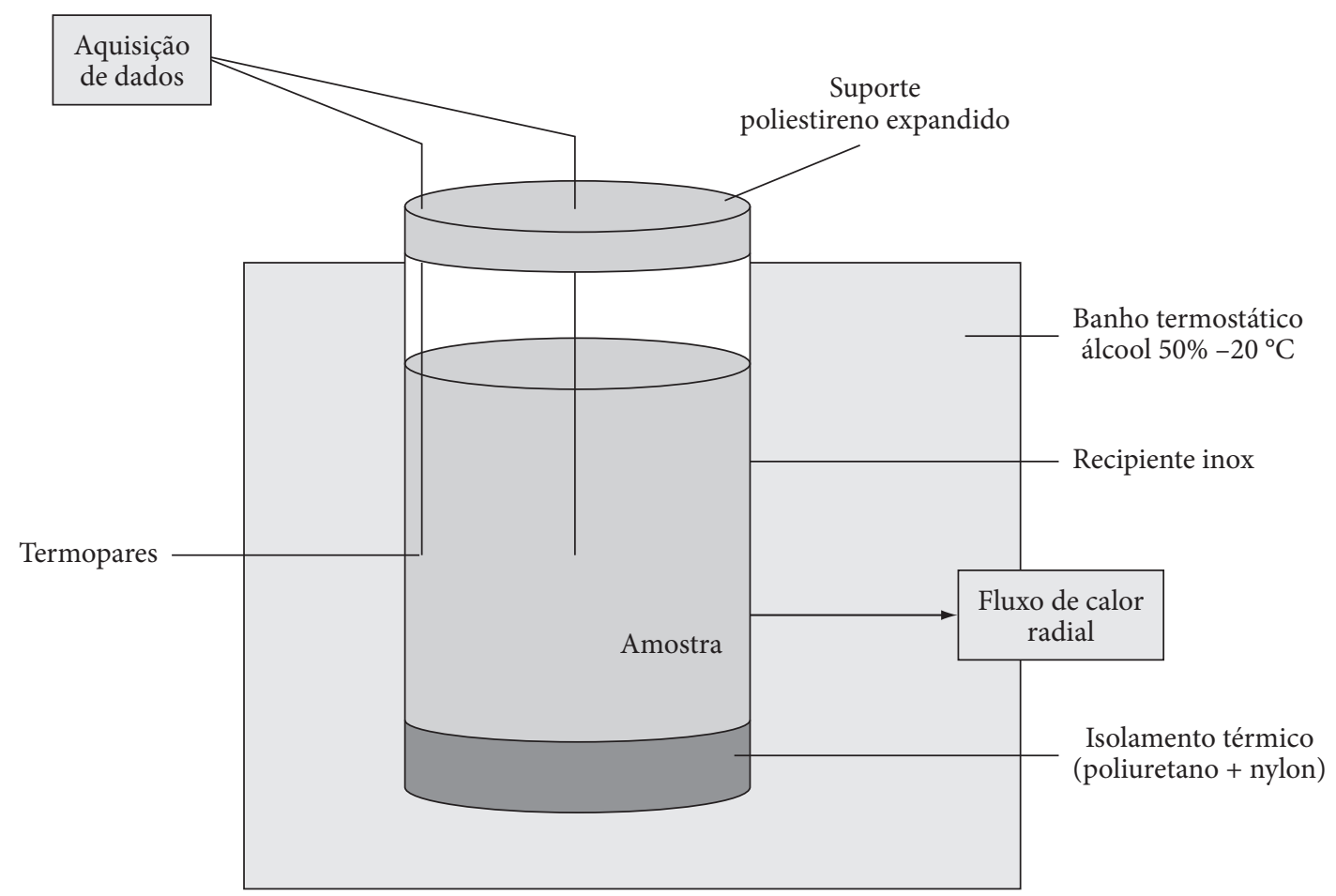

Figura 1. Montagem experimental para o congelamento das polpas de morango. 


\subsection{Dinâmica de congelamento}

A partir dos históricos de congelamento (tempo versus temperatura) foram obtidos os valores da temperatura de início de congelamento. As frações de gelo e água não congelada em função das temperaturas dos sistemas foram estimadas pelas Equações 2, 3 e 4, usando como parâmetros iniciais os valores experimentais obtidos para a umidade e temperatura de início de congelamento.

A estimativa da fração mássica de gelo $\left(\mathrm{X}_{\text {gelo }}\right)$ de alimentos a temperaturas menores que a de início de congelamento foi baseada na Equação (2) derivada da Lei de Raoult (HELDMAN, 1992) com auxílio das Equações (3) e (4).

$\ln X_{A}=\frac{\Delta H_{f}}{R_{g}}\left(\frac{1}{T_{A}}-\frac{1}{T}\right)$

$X_{A}=\frac{\frac{m_{A}}{M_{A}}}{\frac{m_{A}}{M_{A}}+\frac{m_{s}}{M_{s}}}$

$m_{S}=1-m_{A}$

em que:

$\mathrm{X}_{\mathrm{A}}$ = fração molar de água não congelada;

$\Delta \mathrm{H}_{\mathrm{f}}=$ calor latente de fusão da água (6003 J.mol $\left.{ }^{-1}\right)$;

$\mathrm{R}_{\mathrm{g}}=$ constante universal dos gases $\left(8314 \mathrm{~J}_{\mathrm{gmol}}{ }^{-1} \cdot \mathrm{K}\right)$;

$\mathrm{T}_{\mathrm{A}}=$ ponto de congelamento da água $(273,15 \mathrm{~K})$;

$\mathrm{T}=$ temperatura de congelamento do produto $(\mathrm{K})$;

$\mathrm{m}_{\mathrm{A}}=$ fração mássica de água;

$\mathrm{M}_{\mathrm{A}}=$ peso molecular da água;

$\mathrm{m}_{\mathrm{s}}=$ fração mássica de sólidos; e

$\mathrm{M}_{\mathrm{S}}=$ peso molecular efetivo dos sólidos.

\subsection{Caracterização de concentrações polarizadas}

Para a caracterização deste perfil em função das concentrações de aditivos nos sistemas, foram retiradas do cilindro metálico amostras de $5 \mathrm{~g}$ no centro geométrico (raio $=0 \mathrm{~cm}$ ) e na posição de raio igual a $4,5 \mathrm{~cm}$ nos tempos 60, 120 e 180 minutos de congelamento (Figura 2).

Estas amostras foram separadas em frações de sobrenadante e de precipitado por centrifugação (FANEM, Modelo 206 - BL) a $7.155 \times$ g por 40 minutos, quantificadas por pesagem, e os resultados foram expressos em porcentagem de sobrenadante calculado pela Equação (5).

$\% S b=\frac{P_{S}}{P_{T}} \cdot 100$

em que:

$\% \mathrm{Sb}=$ porcentagem de sobrenadante;

$\mathrm{P}_{\mathrm{S}}=$ peso em gramas do sobrenadante resultante da centrifugação; e

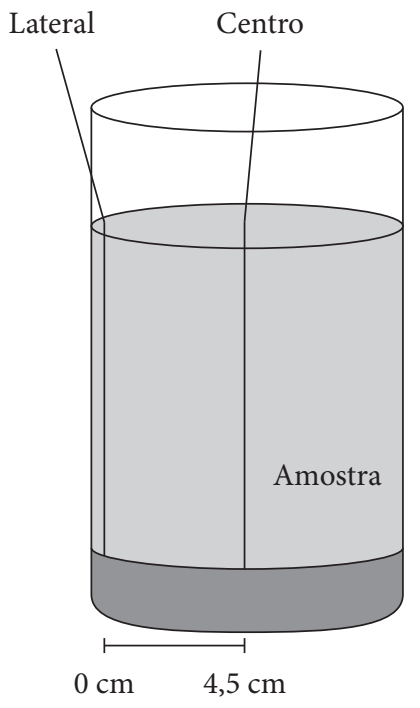

Figura 2. Posições de amostragem da polpa para avaliação de retenção de água.

$\mathrm{P}_{\mathrm{T}}=$ peso em gramas da amostra total centrifugada.

Também foram feitas medidas da atividade de água no precipitado e sobrenadante dos sistemas retirados nos dois pontos da amostra e nos tempos 60, 120 e 180 minutos.

\subsection{Descongelamento}

Amostras de polpa congelada de morango (25 $\pm 1 \mathrm{~g})$ nos 11 tratamentos determinados no delineamento experimental foram descongeladas em ambiente com temperatura controlada de $19 \pm 1{ }^{\circ} \mathrm{C}$. Foram registradas as fotografias logo que a amostra foi retirada do freezer até o descongelamento completo com câmera digital (Sony, modelo DSC-W5), com intervalos de 2 minutos entre cada fotografia.

As fotografias foram tiradas com marcação delimitando $400,0 \mathrm{~cm}^{2}$ (quadrado de 20,0 $\times 20,0 \mathrm{~cm}$ ) e a amostra posicionada no centro. Estas foram avaliadas usando o programa analisador de imagens Quant v.1.0.2. Os aumentos das áreas ocupadas pelas polpas de fruta com diferentes aditivos durante o descongelamento foram quantificados em função do tempo. Os valores das áreas obtidas no Quant foram transformados segundo a Equação (6).

$\% A=\frac{A_{F}-A_{I}}{A_{I}} \cdot 100$

em que:

$\% \mathrm{~A}=$ porcentagem da área;

$\mathrm{A}_{\mathrm{F}}=$ área da amostra no tempo t; e

$\mathrm{A}_{\mathrm{I}}=$ área da amostra no tempo inicial $(\mathrm{t}=0)$.

\subsection{Comportamento reológico}

A caracterização do comportamento reológico dos sistemas constituídos de polpas de morango com adição de sacarose 
e pectina antes e após congelamento/descongelamento foi feita através de leituras em unidades de torque, utilizando viscosímetro analógico (Brookfield, modelo RVT), com precisão de leituras de $\pm 1,0 \%$ e faixa de medição de 100 a 8.000 Pa.s, a $25^{\circ} \mathrm{C}$. Foram utilizadas as velocidades de 0,$5 ; 1 ; 2,5 ; 5 ; 10 ; 20$; 50 e $100 \mathrm{rpm}$, a partir de um volume de $500 \mathrm{~mL}$ de amostra em béquer de $600 \mathrm{~mL}$. Para a polpa de morango, foram usados os spindles cilíndricos de números 2, 3 e 4 de acordo com o limite de leitura na velocidade máxima. Foi utilizada a metodologia de Mitschka (MITSCHKA, 1982; BRIGGS; STEFFE, 1997) para a transformação das leituras em medidas reológicas (tensão de cisalhamento, taxa de deformação e viscosidade aparente).

\subsection{Análises microestruturais}

Os estudos da microestrutura de crescimento dos cristais de gelo nos diferentes sistemas em função do tempo foram feitos através da visualização das amostras durante o congelamento por microscopia fotônica em um microscópio (MEIJI, Série ML 5000), usando um sistema de Cold Stage de Peltier (Physitemp Controller, Modelo TS-4) com temperatura controlada, filtro de luz polarizada e um sistema de vídeo captura. Fotomicrografias foram obtidas em intervalos de 1 segundo após o início do movimento da frente de congelamento.

\subsection{Análise estatística}

As respostas foram obtidas a partir de dois tipos de parcelas experimentais, da mesma amostra: parcela de aproximadamente $500 \mathrm{~g}$ de polpa para as análises de caracterização, congelamento e comportamento reológico e de $25 \mathrm{~g}$ para a avaliação do descongelamento. Os dados foram analisados pela metodologia de superfícies de resposta utilizando os softwares Statistica versão 6.0 (Statsoft $\left.{ }^{\oplus}\right)$ e Minitab 14.

A regressão não linear foi adotada para ajustar os dados da análise do comportamento reológico dos tratamentos pelo modelo de Ostwald-de-Waelle (Lei da Potência) e avaliados quanto ao parâmetro estatístico coeficiente de determinação $\left(R^{2}\right)$. Foram utilizados os softwares $R^{\bullet}$ versão 2.4.1 (R, 2006) e Statistica versão 6.0 (Statsoft $\mathrm{f}^{\oplus}$.

Tabela 2. Médias de atividade de água, pH e acidez titulável dos ensaios antes do congelamento (AC), depois do descongelamento (DD) da polpa de morango e da diferença de cor entre os dados antes do congelamento (AC) e depois do descongelamento (DD)

\begin{tabular}{|c|c|c|c|c|c|c|c|}
\hline \multirow{2}{*}{ Ensaio } & \multicolumn{2}{|c|}{$\mathrm{Aw}$} & \multicolumn{2}{|c|}{$\mathrm{pH}$} & \multicolumn{2}{|c|}{$\mathrm{AT}$} & \multirow{2}{*}{$\Delta \mathrm{E}$} \\
\hline & $\mathrm{AC}$ & $\mathrm{DD}$ & $\mathrm{AC}$ & $\mathrm{DD}$ & $\mathrm{AC}$ & $\mathrm{DD}$ & \\
\hline 1 & 0,993 & 0,993 & 3,26 & 3,32 & 0,92 & 0,85 & 1,24 \\
\hline 2 & 0,984 & 0,983 & 3,35 & 3,31 & 0,80 & 0,78 & 3,23 \\
\hline 3 & 0,994 & 0,992 & 3,41 & 3,23 & 1,03 & 1,36 & 3,26 \\
\hline 4 & 0,985 & 0,983 & 3,45 & 3,29 & 0,84 & 1,06 & 4,68 \\
\hline 5 & 0,989 & 0,990 & 3,56 & 3,57 & 0,60 & 0,71 & 2,56 \\
\hline 6 & 0,972 & 0,972 & 3,59 & 3,64 & 0,74 & 0,78 & 6,16 \\
\hline 7 & 0,975 & 0,979 & 3,78 & 3,84 & 0,80 & 0,87 & 1,21 \\
\hline 8 & 0,995 & 0,996 & 3,58 & 3,59 & 0,77 & 0,73 & 2,50 \\
\hline 9 & 0,981 & 0,984 & 3,62 & 3,50 & 0,63 & 0,57 & 4,79 \\
\hline 10 & 0,993 & 0,990 & 3,67 & 3,60 & 0,82 & 0,81 & 1,43 \\
\hline 11 & 0,985 & 0,984 & 4,08 & 3,57 & 0,73 & 0,69 & 1,40 \\
\hline
\end{tabular}

\section{Resultados e discussão}

\subsection{Propriedades físico-químicas}

A Tabela 2 mostra as médias dos resultados das análises físico-químicas feitas para a caracterização das polpas de morango com adição de sacarose e pectina antes e após os processos de congelamento e descongelamento.

A adição das concentrações de sacarose e pectina estudadas não influenciou significativamente nas respostas apresentadas na Tabela 2, comprovando que essas características de qualidade se mantiveram com os tratamentos.
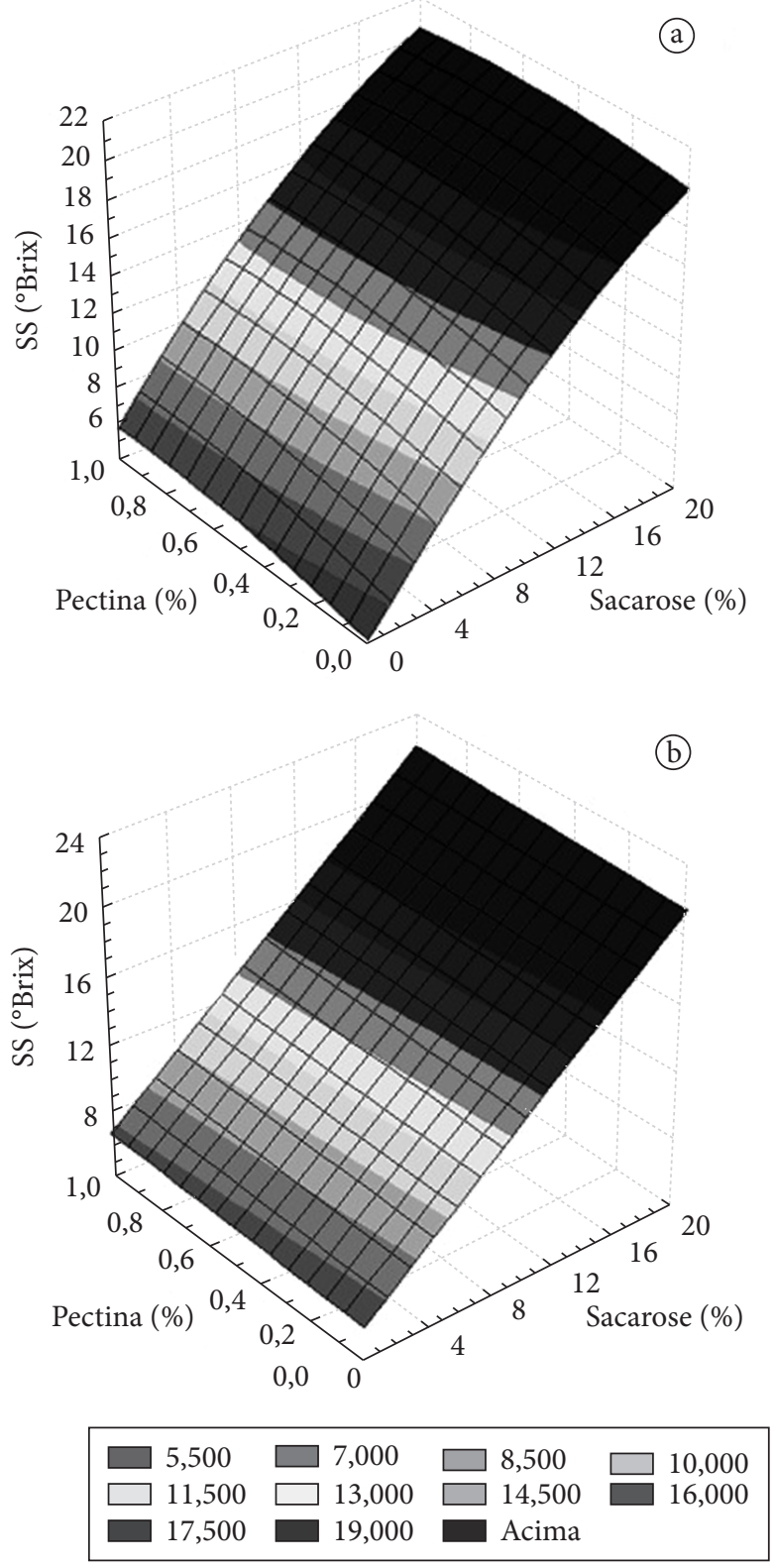

Figura 3. Superfícies de resposta de sólidos solúveis - relação entre as porcentagens de adição de sacarose e de pectina para polpa de morango antes do congelamento (a) e depois do descongelamento (b). 
No espaço de cores $\mathrm{L}^{*} \mathrm{a}^{*} \mathrm{~b}^{*}$, a diferença de cor pode ser expressa com um único valor, $\Delta \mathrm{E}^{\star}$ (MINOLTA, 1994). Pelos dados encontrados a partir da análise de regressão dos parâmetros de cor, observou-se que o $\Delta \mathrm{E}^{\star}$ não teve diferença significativa (ao nível de $5 \%$ de probabilidade) em relação à adição de sacarose e pectina. Os valores de tonalidade e saturação também não diferiram significativamente entre os tratamentos.

Os parâmetros usados para analisar a qualidade dos ajustes foram o F-estatístico, o coeficiente de determinação $\left(\mathrm{R}^{2}\right)$ e os gráficos de resíduos. Estes possibilitam se ter uma medida da proporção da variação dos valores experimentais em torno da média explicada pelo modelo ajustado. Verifica-se na Tabela 1 que os ensaios 5, 6 e 7 referem-se àqueles constituídos de $10 \%$ de sacarose e $0,5 \%$ de pectina e deveriam fornecer médias aproximadas o que não acontece quando se observa a Tabela 2. Esta grande variação no valor de $\Delta \mathrm{E}$ para o mesmo tratamento compromete a qualidade do ajuste com grande variância nos resíduos que são por definição a diferença entre os valores da resposta real observada e aquelas preditas para esta resposta usando o modelo ajustado.

As concentrações de adição de sacarose e pectina não influenciaram na atividade de água das amostras e os valores antes do congelamento e depois do descongelamento foram muito próximos. O processo de congelamento simplesmente passa a água do alimento do estado líquido para o sólido, não interferindo na quantidade desta depois do descongelamento.

Os resultados para o teor de sólidos solúveis totais ( $\left.{ }^{\circ} \mathrm{Brix}\right)$ antes do congelamento e depois do descongelamento em função das concentrações de sacarose e pectina adicionadas às polpas de morango estão mostrados nas superfícies de resposta da Figura 3.

O teor de sólidos solúveis totais (SS) é utilizado como uma medida indireta do teor de açúcares, uma vez que aumenta de

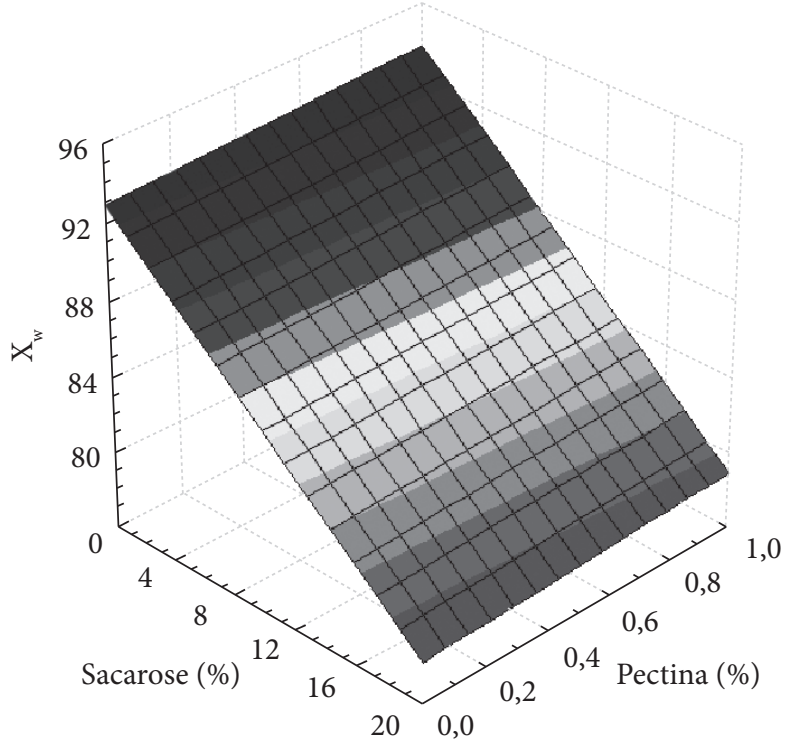

Figura 4. Superfície de resposta da umidade em função da adição de sacarose e de pectina em polpas de morango. valor à medida que esses teores vão se acumulando na fruta. A sua medição não representa o teor exato dos açúcares, pois outras substâncias também se encontram dissolvidas na seiva vacuolar (vitaminas, fenólicos, pectinas, ácidos orgânicos, etc.); no entanto, entre essas, os açúcares são as mais representativas, chegando a constituir até 85-90\% dos SS (CHITARRA, M. I. F; CHITARRA, A. B., 2005). Por estes motivos a adição de sacarose foi o fator que influenciou no incremento da concentração de sólidos solúveis das amostras.

A Figura 4 mostra a superfície de resposta obtida para as umidades $\left(\mathrm{X}_{\mathrm{w}}\right)$ das polpas de morango em função das concentrações de sacarose e pectina.

A adição de sacarose teve efeito significativo ( $p<5 \%)$ na umidade das polpas de morango. Observa-se na Figura 4 que quanto maior a concentração de sacarose adicionada menor é o teor de umidade final da polpa.

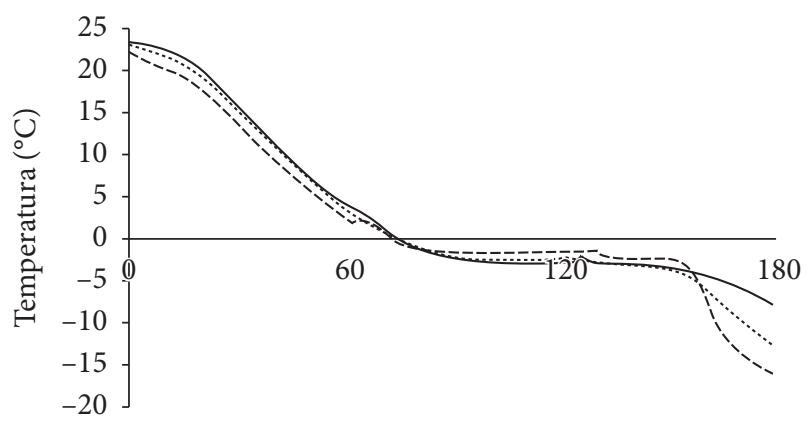

Tempo (minutos)

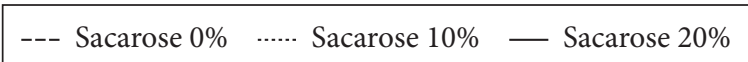

Figura 5. Históricos de temperatura para o congelamento de polpas de morango com adição de pectina $0,5 \%$ e diferentes concentrações de sacarose.

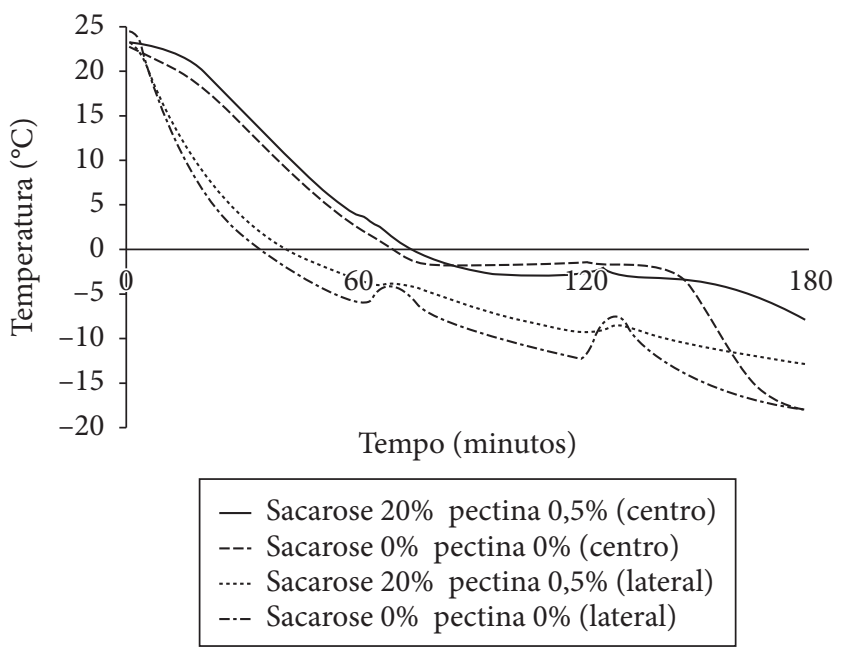

Figura 6. Históricos de congelamento de polpas de morangos com e sem adição de sacarose e pectina obtidos pela leitura de sensores instalados no centro geométrico e na lateral dos cilindros metálicos usados para o congelamento. 


\subsection{Avaliação da dinâmica de congelamento das polpas em função da concentração de aditivos}

\section{Históricos de temperatura}

A Figura 5 mostra o efeito da concentração de sacarose adicionada sobre a redução da temperatura de congelamento e sobre o tempo de congelamento em polpas de morangos com adição de pectina em concentração de 0,5\%.

A Figura 6 mostra os históricos de temperatura obtidos pela leitura de termopares localizados no centro geométrico (raio $=0 \mathrm{~cm}$ ) e a uma distância radial de $4,5 \mathrm{~cm}$ e altura de $3 \mathrm{~cm}$ no cilindro (lateral) usado nos procedimentos de congelamento para os sistemas constituídos de polpas de morango com sacarose $0 \%$ - pectina $0 \%$ e sacarose $20 \%$ - pectina $0,5 \%$. Os picos observados na Figura 6, mais notáveis para o tratamento constituído de sacarose $20 \%$ e pectina $0 \%$, são decorrentes de flutuações de temperatura produzidas pela retirada do cilindro do meio refrigerante nos tempos de 60, 120 e 180 minutos para a coleta de amostras para a análise das concentrações polarizadas.

O fluxo de calor da frente de congelamento diminui conforme a frente penetra no produto. Este fato se deve ao aumento da resistência térmica da parte congelada localizada entre a superfície refrigerada e a frente de congelamento. No caso de geometrias cilíndricas, a resistência térmica aumenta enquanto as camadas de gelo são formadas, o volume a ser congelado é cada vez menor conforme a frente de congelamento aumenta quando se afasta da superfície (CHEVALIER; LEBAIL; GHOUL, 2000).

Ota (2006) estudou o congelamento de pão francês e observou que em algumas curvas de congelamento não foi possível observar a etapa de congelamento como, por exemplo, através do histórico da temperatura em $\mathrm{r}=27 \mathrm{~mm}$ (superfície do produto). Isto se deve ao fato do sensor de temperatura estar localizado próximo à superfície da amostra, pois o congelamento ocorre da superfície para o centro e, no início do congelamento, o fluxo de calor é maior (Figura 6).

\section{Efeito dos aditivos sobre a temperatura de congelamento inicial dos sistemas}

As temperaturas de congelamento de soluções ideais de mono e bicomponentes podem ser descritas pela Lei de Raoult e a complexidade da composição bioquímica e textura de polpas de frutas exige uma investigação experimental específica da temperatura de início de congelamento de cada produto. A temperatura de início de congelamento de polpas de frutas depende dos mesmos fatores descritos para soluções ideais, sendo o teor de sólidos de importância básica. Quanto mais alto o teor de sólidos, mais baixo será o ponto de congelamento incipiente (FERREIRA; GUIMARÃES; MAIA, 2007).

Os históricos de temperatura mostraram que as presenças de géis de pectina de alto peso molecular praticamente não exerceram efeitos notáveis sobre a queda da temperatura de congelamento, mas influenciaram ligeiramente o tempo de congelamento do fruto no centro térmico. Ao contrário, a presença de substâncias tais como sacarose que têm suas moléculas dispersas em solução aquosa, diminuiu notavelmente a temperatura de congelamento inicial do sistema. Resultados similares foram observados por Hoo, McLellan (1987), estudando a adição de pectina ao suco de maçã de diferentes concentrações e por Budiaman, Fennema (1987), medindo a temperatura crioscópica de hidrocoloides dentre eles CMC em presença de sacarose $4 \%$.

Os valores médios da umidade, temperatura de início de congelamento $\left(\mathrm{T}_{\mathrm{ic}}\right)$ e peso molecular efetivo de sólidos $\left(\mathrm{M}_{\mathrm{s}}\right)$ para

Tabela 3. Valores médios da umidade, temperatura de início de congelamento $\left(\mathrm{T}_{\mathrm{ic}}\right)$ e peso molecular efetivo de sólidos $\left(\mathrm{M}_{\mathrm{s}}\right)$ para as polpas de morango com diferentes concentrações de sacarose e pectina

\begin{tabular}{cccccc}
\hline Tratamentos & \% sacarose & \% pectina & $\begin{array}{c}\text { Umidade } \\
\text { (\%peso/peso) }\end{array}$ & $\mathrm{T}_{\mathrm{ic}}$ & $\mathrm{M}_{\mathrm{s}}$ \\
\hline 1 & 2,91 & 0,15 & 91,38 & $-0,9$ & 193,67 \\
2 & 17,09 & 0,15 & 80,58 & $-2,2$ & 200,13 \\
3 & 2,91 & 0,85 & 91,89 & $-0,7$ & 233,24 \\
4 & 17,09 & 0,85 & 80,01 & $-1,5$ & 306,11 \\
5 & 10,0 & 0,50 & 85,32 & $-1,9$ & 165,85 \\
6 & 10,0 & 0,50 & 85,26 & $-1,8$ & 176,17 \\
7 & 10,0 & 0,50 & 85,23 & $-2,1$ & 150,86 \\
8 & 0 & 0,50 & 93,17 & $-0,8$ & 169,41 \\
9 & 20 & 0,50 & 79,56 & $-2,3$ & 203,97 \\
10 & 10,0 & 0 & 85,77 & $-1,4$ & 218,12 \\
11 & 10,0 & 1,0 & 87,33 & $-2,2$ & 120,39 \\
Referência & 0 & 0 & 94,35 & $-0,7$ & 158,35 \\
\hline
\end{tabular}
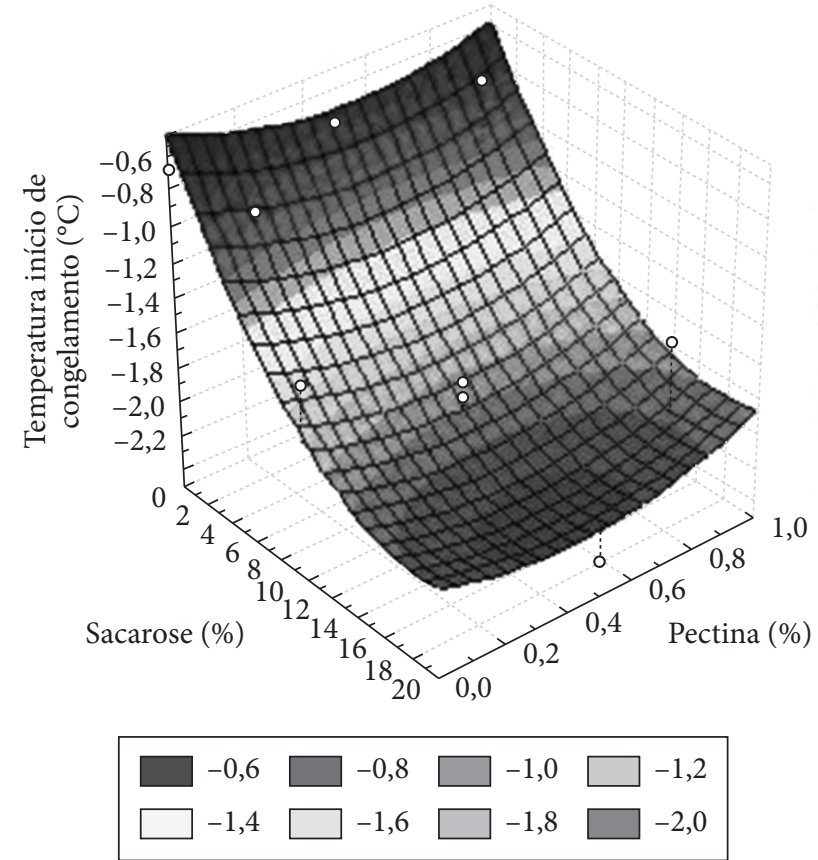

Figura 7. Superfície de resposta para a temperatura de início de congelamento em função das concentrações de sacarose e pectina adicionadas a polpas de morango $\left(\mathrm{R}^{2}=0,8224\right.$, F-estatístico $=20,8391$, $\mathrm{p}>\mathrm{F}=0,00042$ ). 
as polpas de morango com diferentes concentrações de sacarose e pectina estão apresentados na Tabela 3.

Os resultados mostrados na Tabela 3 são compatíveis com aqueles obtidos por Jie, Lite e Yang (2003). Estes verificaram que a temperatura de início de congelamento do morango está entre $-0,8$ e $-0,77^{\circ} \mathrm{C}$ e comprovaram também que o ponto de início de congelamento é mais baixo para frutos inteiros que para suas respectivas polpas ou sucos pela presença de parede celular na fruta, o que dificulta a saída da água intracelular para a formação dos cristais de gelo.

O efeito da presença de aditivos sobre a redução da temperatura de início de congelamento também pode ser observado nos resultados apresentados na Tabela 3. A Figura 7 mostra a superfície de resposta ajustada pelo modelo quadrático indicando a tendência de que quanto maior a concentração de sacarose mais baixa é a temperatura de início de congelamento. Observa-se também que existe um efeito da pectina na redução da temperatura de início de congelamento em sistemas com concentrações intermediárias em torno de 0,5\% (Figura 7).
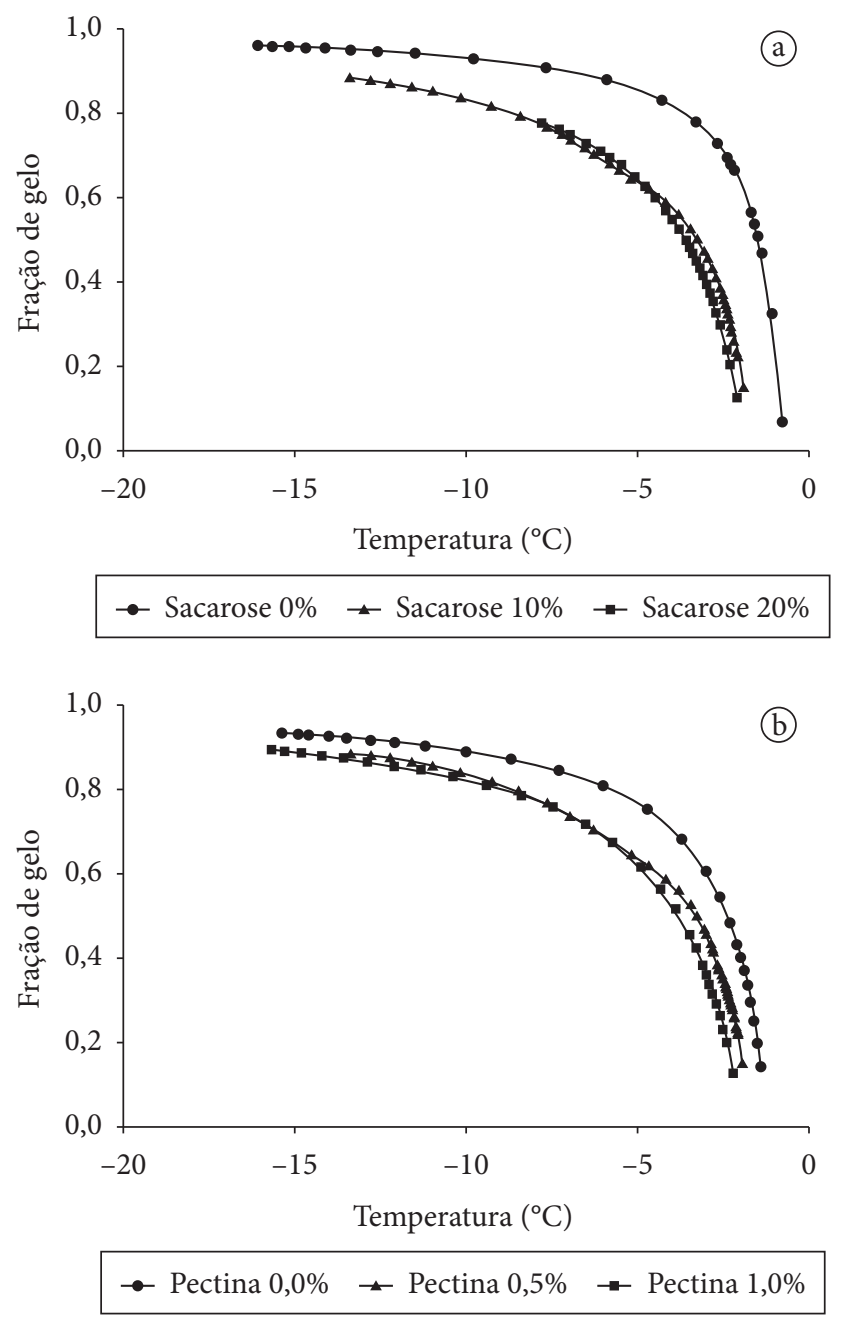

Figura 8. (a) Fração de gelo estimado em função da temperatura durante o congelamento de polpas de morango com adição de (a) pectina $0,5 \%$ e diferentes concentrações de sacarose; (b) sacarose $10 \%$ e diferentes concentrações de pectina.
Efeito dos aditivos sobre a fração de gelo em função do tempo em polpas de morango congeladas

O procedimento para o cálculo da fração de gelo utilizando as Equações (2), (3) e (4) tem como parâmetros de entrada as temperaturas de congelamento iniciais apresentadas na Tabela 3, que permitem a determinação do peso molecular efetivo dos sólidos $\left(\mathrm{M}_{\mathrm{S}}\right)$, substituindo o valor de $\mathrm{X}_{\mathrm{A}}$. Os valores de $M_{S}$ encontrados para os diferentes sistemas em função dos teores de umidade obtidos experimentalmente também estão apresentados na Tabela 3.

Conhecendo $\mathrm{M}_{\mathrm{S}}$, os valores da fração de água não congelada e da fração de gelo em função da temperatura para os diferentes sistemas são obtidos reutilizando as Equações (2), (3) e (4), sendo a temperatura dos sistemas agora o único parâmetro de entrada. Valores estimados da fração de gelo em função da temperatura dos sistemas enfatizando o efeito das concentrações de sacarose e de pectina adicionadas em polpas de morangos estão apresentados nos gráficos da Figura 8. As estimativas consideram que cristais de gelo puro são formados durante o congelamento e que todo o soluto está concentrado na água não congelada.

Verifica-se pelos gráficos que em sistemas que envolvem a adição de sacarose, nesta faixa de temperatura, os valores estimados da fração de gelo são notavelmente inferiores àqueles obtidos com os demais tratamentos. Este comportamento está associado à diferença na composição do fruto, principalmente em relação ao teor de água.

O movimento da frente de congelamento nos recipientes cilíndricos metálicos imersos no banho ultratermostático ocorre simetricamente na direção da superfície externa para o centro. Considerando que a temperatura do banho é constante e o fluxo de calor é unidimensional na direção radial uma vez que o fundo

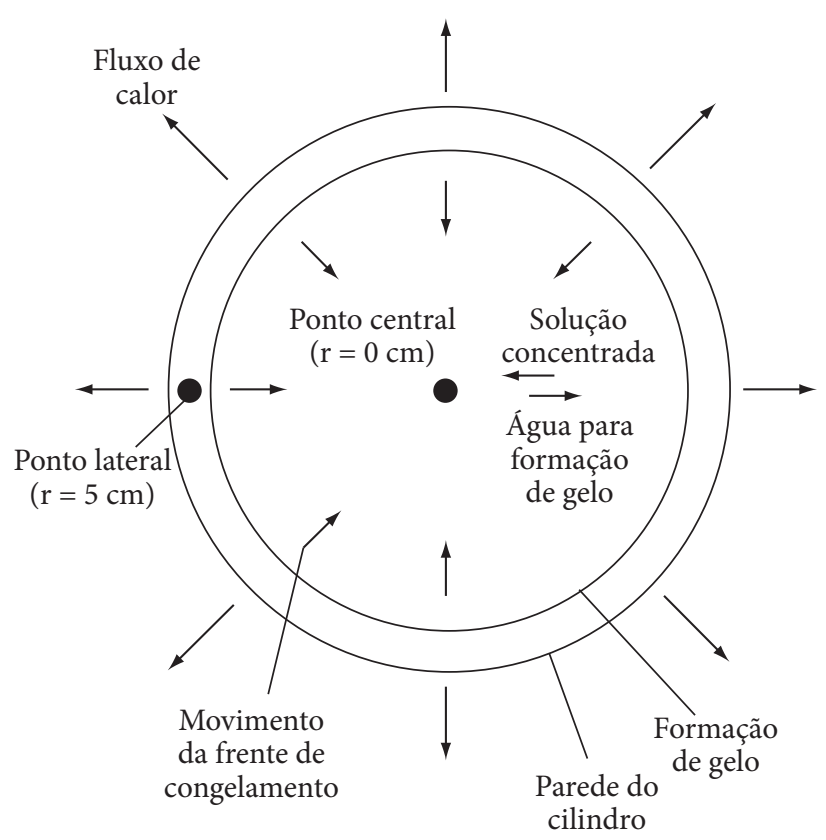

Figura 9. Modelo proposto para avanço da frente de congelamento. 
do recipiente está isolado e considerando um cilindro infinito, o movimento da frente de congelamento durante o processo pode ser entendido pelo modelo esquematizado na Figura 9.

A Figura 10 mostra as estimativas da fração de gelo em função da temperatura e do histórico de temperatura para as polpas de morango constituídas de pectina $0,5 \%$ e diferentes concentrações de sacarose nos pontos de coordenadas $r=0$ (central) e raio $=4,5 \mathrm{~cm}$ (próximo à superfície) nos tempos 60 , 120 e 180 minutos de congelamento.

Observa-se na Figura 10 que a adição de sacarose à polpa diminui a fração de gelo em função do tempo. O efeito da concentração de sacarose sobre a formação de gelo próximo à superfície do recipiente metálico está evidente na Figura 10 (a) que mostra uma tendência que se apresenta com menos intensidade, até o congelamento completo aos 180 minutos. As polpas adicionadas de altas concentrações de sacarose apresentam menores frações de gelo e a formação de cristais de gelo no centro da amostra (Figura 10b) é mais lenta em decorrência do processo de transferência de calor ser na direção radial e da concentração por polarização em que acontece a
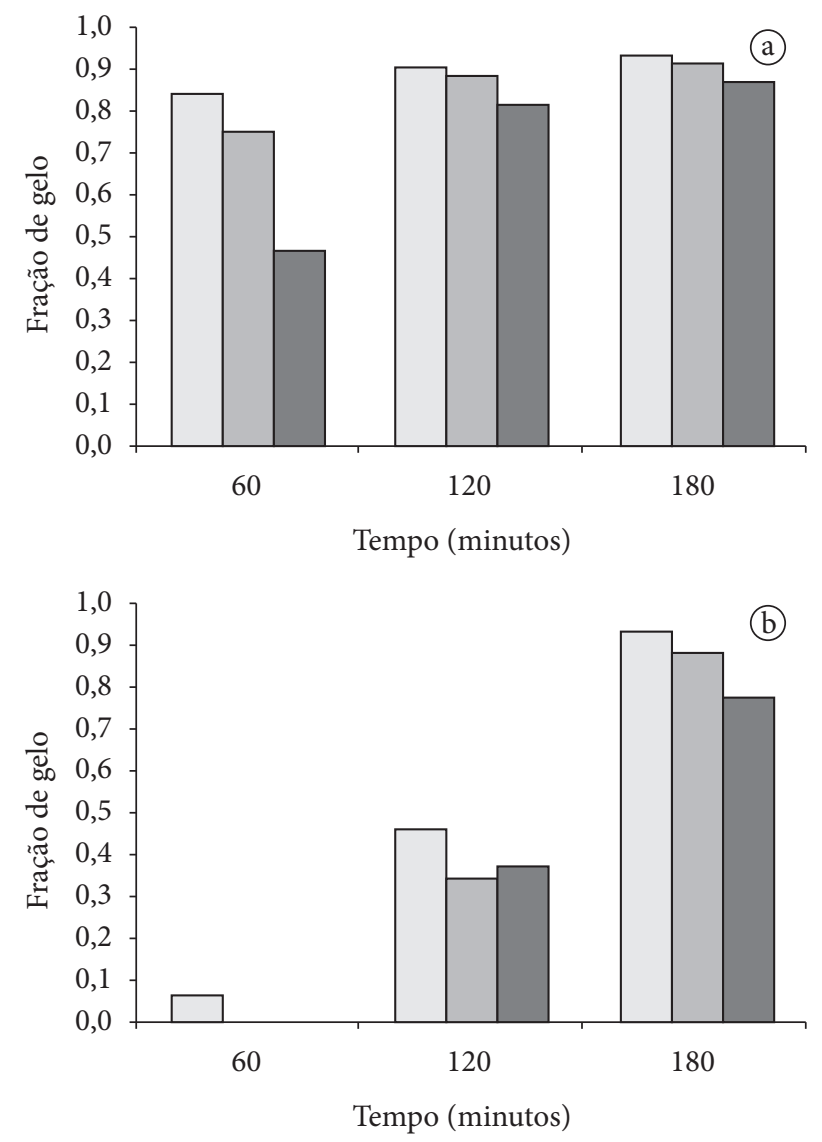

Sacarose 0\% $\square$ Sacarose $10 \% \quad \square$ Sacarose 20\%

Figura 10. Histogramas das frações mássicas de gelo em função do tempo de congelamento na superfície (a) e no centro do cilindro (b) para as polpas de morango tratadas com $0,5 \%$ de pectina e diferentes concentrações de sacarose. migração de água em direção à superfície para formação dos cristais de gelo e concentração dos solutos em direção ao centro conforme modelo proposto na Figura 9.

A Figura 11 mostra as estimativas da fração de gelo estimadas em função da temperatura e do histórico de temperatura para as polpas de morango constituídas de sacarose $10 \%$ e diferentes concentrações de pectina no ponto de coordenada $\mathrm{r}=0$ (central) nos tempos 60, 120 e 180 minutos de congelamento.

Nestes sistemas verifica-se que, para a concentração de 0,5\% de pectina (Figura 11), no tempo de 120 minutos, existe uma grande fração de gelo no sistema quando comparado com os demais tratamentos. A atenção é voltada para este sistema uma vez que a fração de gelo, embora seja uma estimativa, foi calculada baseada nas temperaturas de início de congelamento e umidades iniciais das amostras que foram obtidas experimentalmente.

\section{Efeito dos aditivos sobre a concentração polarizada}

A Figura 12 apresenta superfícies de resposta mostrando a relação percentual entre as massas de sobrenadante e a massa total de amostras coletadas nos pontos de coordenadas $\mathrm{r}=0 \mathrm{~cm}$ (centro) e $\mathrm{r}=4,5 \mathrm{~cm}$, nos tempos de 60,120 e 180 minutos.

Observa-se que, para os sistemas constituídos de polpas de morango com diferentes concentrações de sacarose e pectina, $o$ fenômeno de concentração polarizada decorrente da separação da fase gelo e da fase não congelada não mostrou diferença significativa com todas as superfícies localizadas no mesmo plano e as colunas dos histogramas praticamente no mesmo nível.

\section{Análise do tempo de derretimento}

As Figuras 13, 14 e 15 apresentam fotografias obtidas durante o descongelamento de sistemas constituídos de polpa de morango com $0,5 \%$ de pectina e $0 \%$ de sacarose (Figura 13), $10 \%$ de sacarose (Figura 14) e 20\% de sacarose (Figura 15).

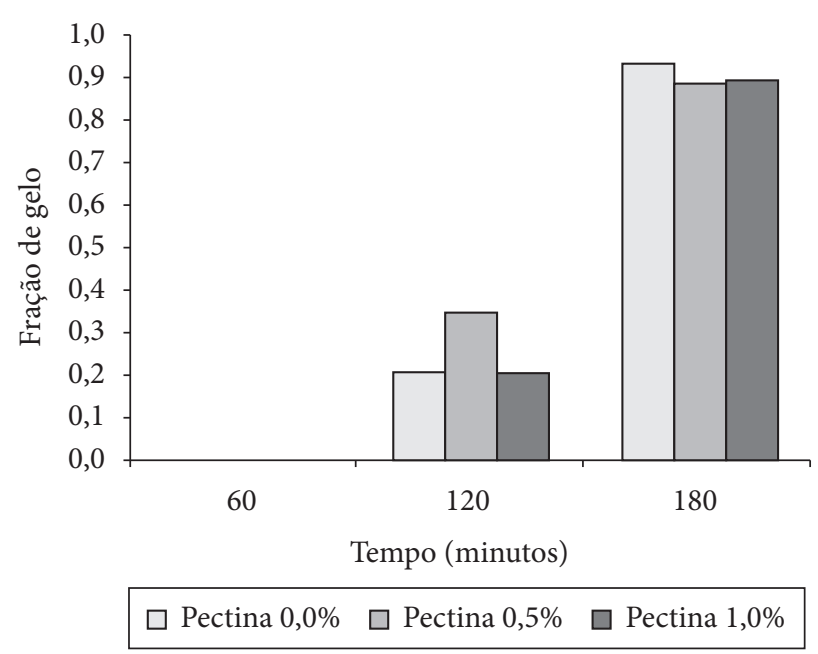

Figura 11. Histogramas das frações mássicas de gelo em função do tempo de congelamento no centro do cilindro para as polpas de morango tratadas com $10 \%$ de sacarose e diferentes concentrações de pectina. 
(a1)
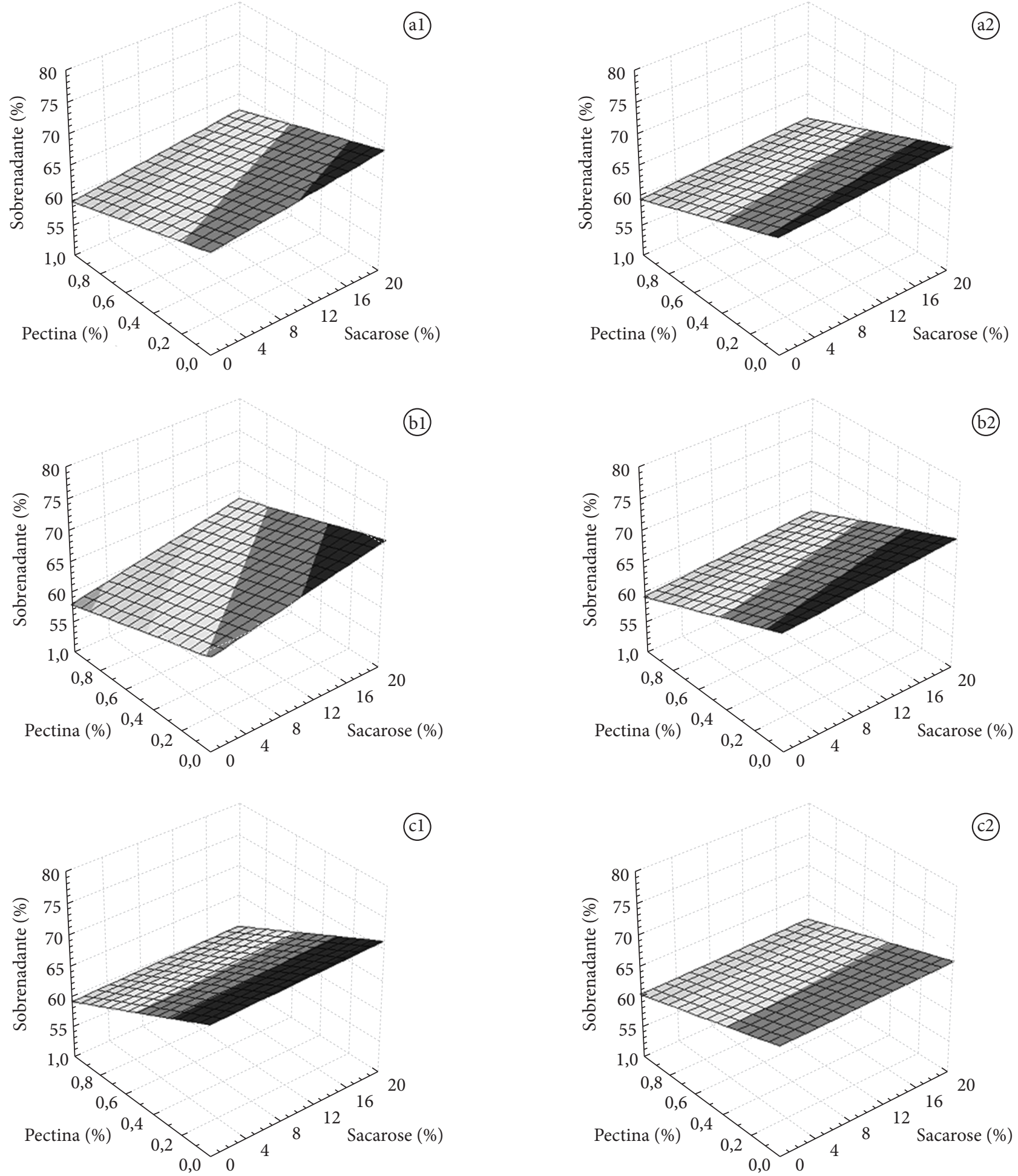

$\square 0,000 \square 53,000 \square 56,000 \square 59,000 \quad \square 62,000 \square 65,000$
$68,000 \quad \square 71,000 \quad \square 7,000 \quad \square 77,000 \quad \square$ Acima

Figura 12. Representações dos comportamentos da porcentagem de sobrenadante resultante da centrifugação dos sistemas de polpas de morangos nos tempos (a) 60, (b) 120 e (c) 180 minutos de congelamento nas posições central (1) e lateral (2). 
As superfícies de resposta do aumento percentual da área durante o descongelamento da polpa de morango com sacarose e pectina em função do tempo, compreendendo todos os sistemas estudados, pode ser observada na Figura 16.

A concentração de pectina também influencia os tempos de descongelamento, sendo o sistema que apresenta a menor temperatura de início de congelamento, de acordo com a Tabela $3\left(\mathrm{~T}_{\mathrm{ic}}=-2,2^{\circ} \mathrm{C}\right)$, aquele que apresenta um processo de descongelamento mais rápido ( $10 \%$ sacarose e $1 \%$ de pectina).

Dentre os tratamentos de polpas de morango com adição de sacarose e pectina, o tempo de descongelamento mais lento foi obtido para aquele constituído de sacarose $10 \%$ e pectina $0,5 \%$, que apresentou um tempo de descongelamento de 94 minutos.

A Figura 16 confirma que quanto maior a concentração de sacarose, maior é o aumento percentual de área e mais rápido é o processo de derretimento.

Entre os tratamentos de polpa de morango constituídos de $0,5 \%$ de pectina com adição de sacarose em diferentes concentrações, o sistema com concentração de $20 \%$ de sacarose foi o que apresentou descongelamento mais rápido nas mesmas condições ambientais. Como mostrado na Tabela 3, este

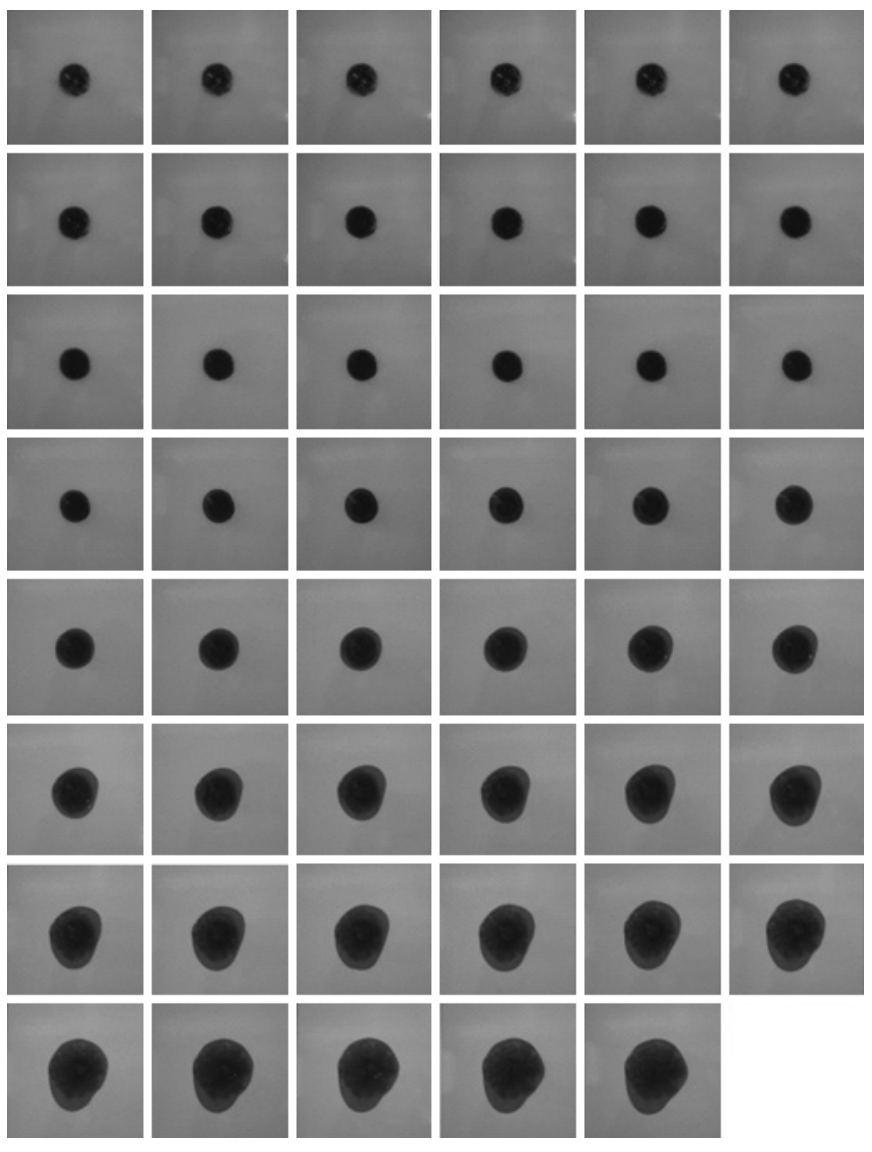

Figura 13. Fotografias obtidas durante o descongelamento (de $2 \mathrm{em}$ 2 minutos) de sistemas constituídos de polpa de morango com $0,5 \%$ de pectina e $0 \%$ de sacarose.

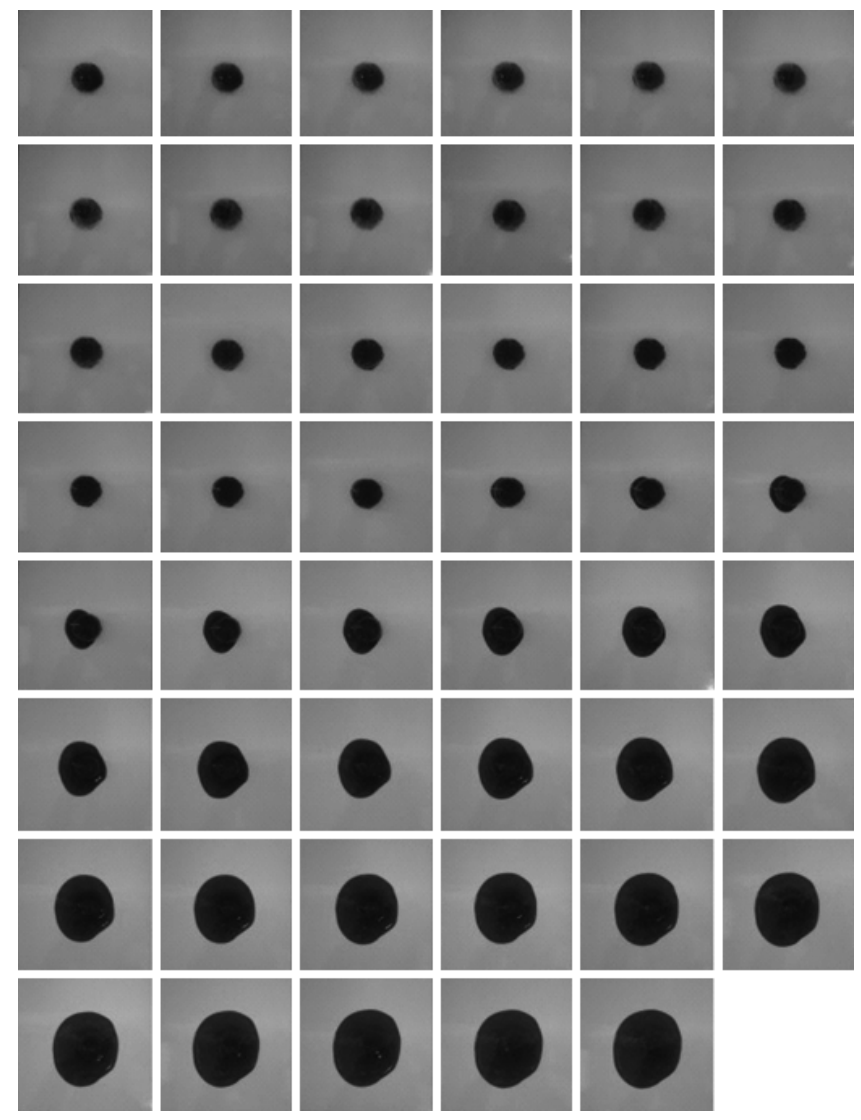

Figura 14. Fotografias obtidas durante o descongelamento (de 2 em 2 minutos) de sistemas constituídos de polpa de morango com $0,5 \%$ de pectina e $10 \%$ de sacarose.

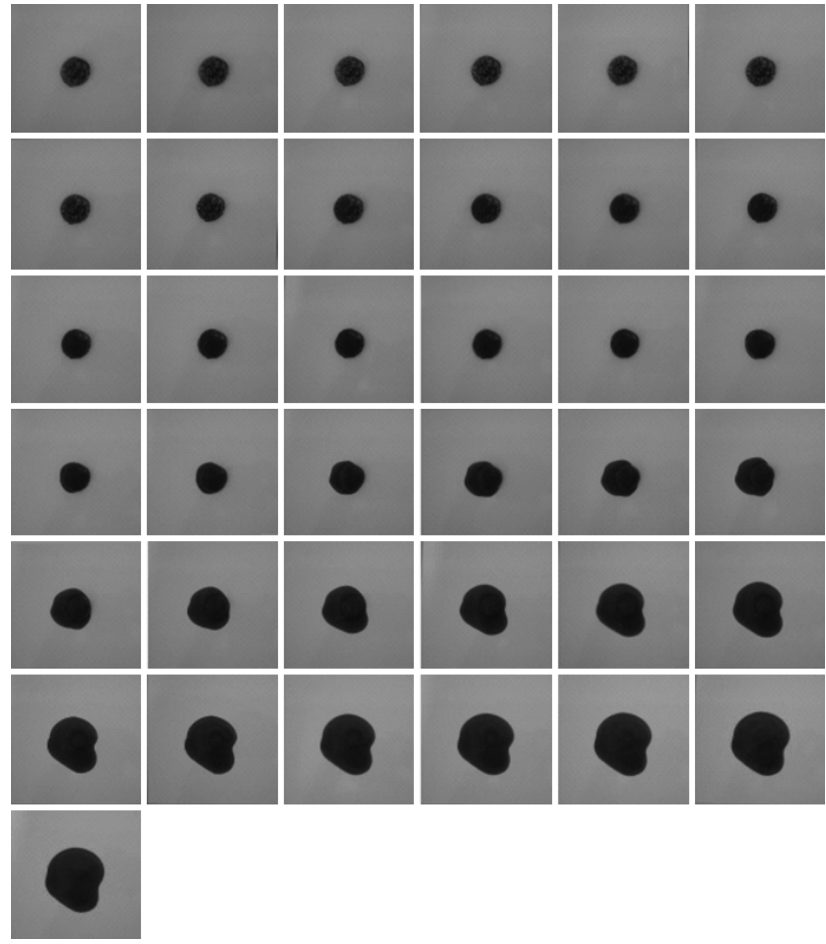

Figura 15. Fotografias obtidas durante o descongelamento (de 2 em 2 minutos) de sistemas constituídos de polpa de morango com $0,5 \%$ de pectina e $20 \%$ de sacarose. 

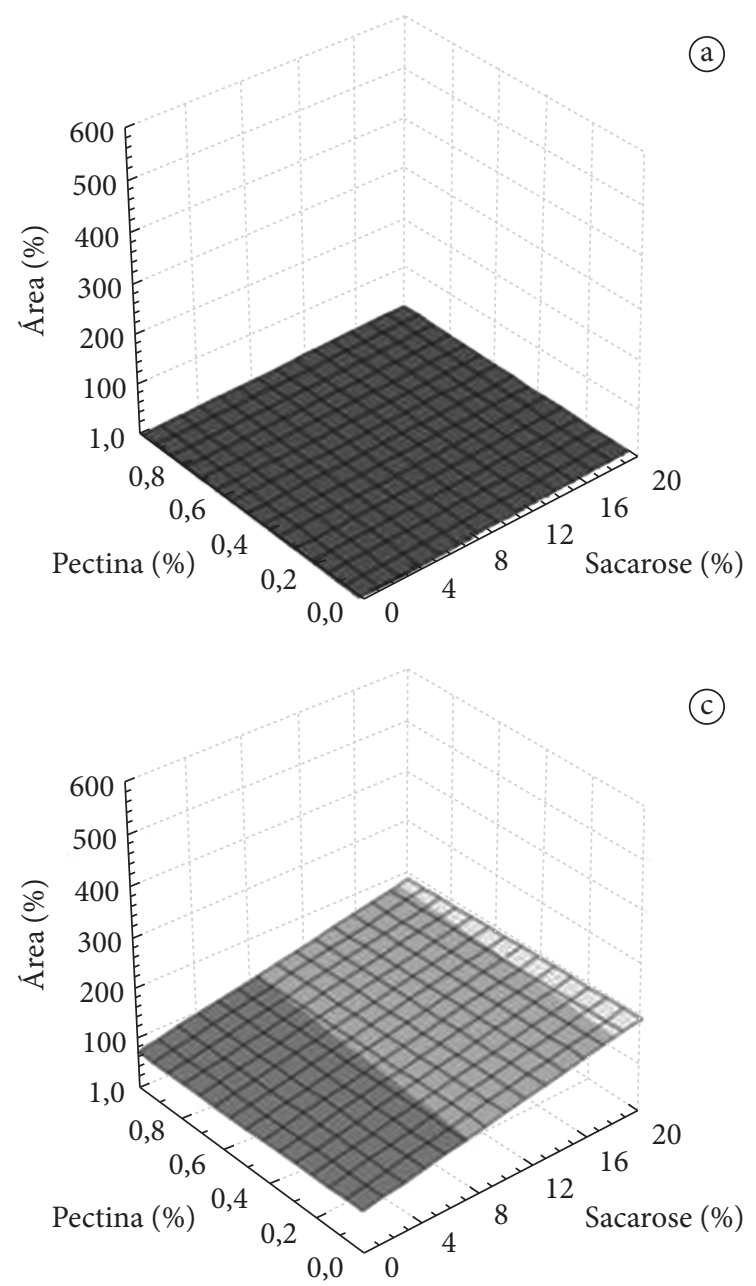

(e)

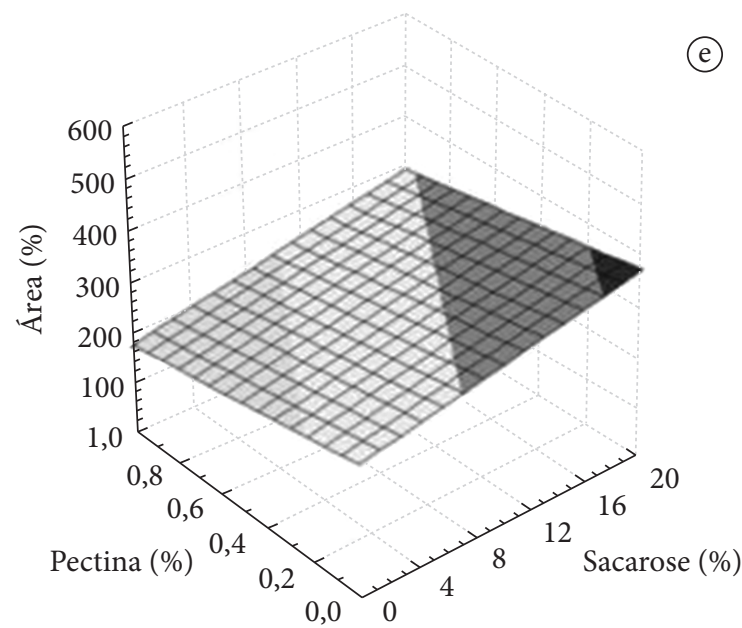

(b)
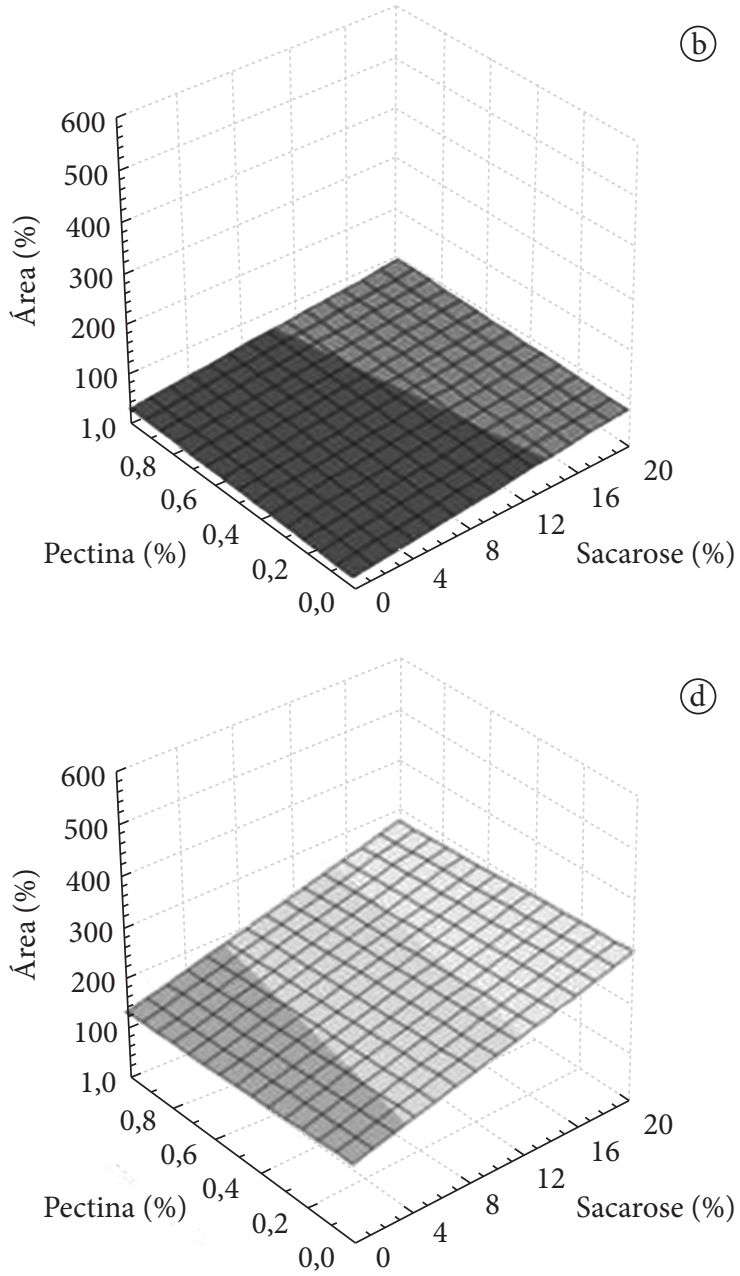

(d)

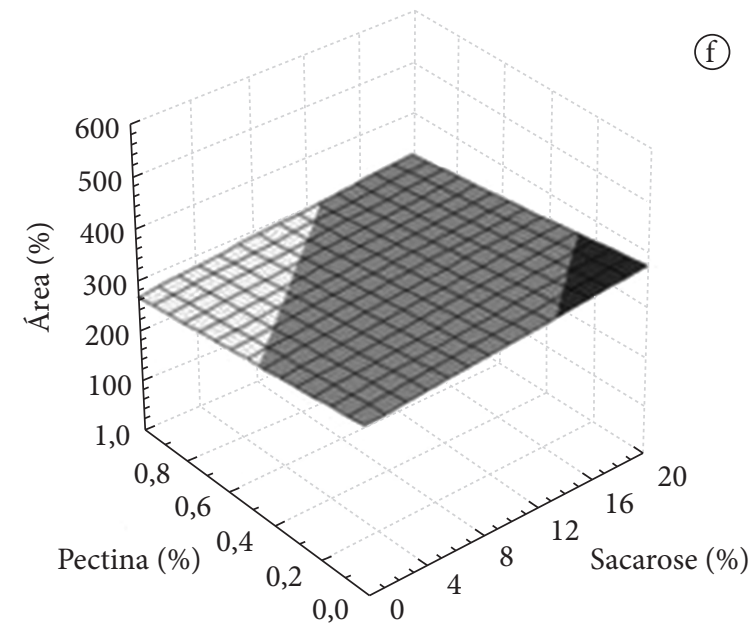

(f)

0,000

60,000

120,000

180,000

$240,000 \square 300,000$

480,000

540,000

Figura 16. Superfícies de resposta da porcentagem de aumento da área descongelada da polpa de morango em função da adição de sacarose e pectina, nos tempos 40, 50, 60, 70, 80 e 90 minutos (a, b, c, d, e, f, respectivamente). 
tratamento é o que apresenta a menor temperatura de início de congelamento $\left(\mathrm{T}_{\text {ic }}=-2,3^{\circ} \mathrm{C}\right)$.

Tecidos, géis e outros materiais aquosos que transmitem calor fundamentalmente por condução apresentam tempos de descongelamento maiores do que os de congelamento, considerando-se diferenciais de temperatura iguais (COLLA; PRENTICE-HERNANDEZ, 2003).

No congelamento, ocorre a remoção de calor latente de cristalização através da camada de gelo que aumenta com o tempo e pela diminuição da temperatura do produto que está sendo congelado. Uma vez que o gelo tem condutividade e difusividade térmicas elevadas, o congelamento ocorre rapidamente. Por outro lado, o descongelamento envolve adição de calor latente de fusão através da camada de água

Tabela 4. Estimativas dos parâmetros do modelo Ostwald-de-Waelle (Lei da Potência) para polpa de morango antes do congelamento

\begin{tabular}{ccccccc}
\hline Ensaio & $\begin{array}{c}\text { Sacarose } \\
(\%)\end{array}$ & $\begin{array}{c}\text { Pectina } \\
(\%)\end{array}$ & $\mathrm{n}$ & $\mathrm{K}$ & $\begin{array}{c}\text { Erro } \\
\text { padrão }\end{array}$ & $\begin{array}{c}\mathrm{R}^{2} \\
(\%)\end{array}$ \\
\hline 1 & 2,91 & 0,15 & 0,301 & 2,982 & 0,143 & 99,80 \\
2 & 17,09 & 0,15 & 0,352 & 2,307 & 0,117 & 99,86 \\
3 & 2,91 & 0,85 & 0,396 & 4,282 & 0,170 & 99,94 \\
4 & 17,09 & 0,85 & 0,429 & 3,313 & 0,120 & 99,96 \\
5 & 10,00 & 0,50 & 0,397 & 2,279 & 0,154 & 99,83 \\
6 & 10,00 & 0,50 & 0,375 & 4,062 & 0,247 & 99,83 \\
7 & 10,00 & 0,50 & 0,381 & 3,771 & 0,203 & 99,88 \\
8 & 20,00 & 0,50 & 0,330 & 3,903 & 0,264 & 99,69 \\
9 & 0,00 & 0,50 & 0,393 & 3,108 & 0,126 & 99,94 \\
10 & 10,00 & 1,00 & 0,299 & 3,597 & 0,218 & 99,68 \\
11 & 10,00 & 0,00 & 0,442 & 2,851 & 0,121 & 99,95 \\
Referência & 0 & 0 & 0,273 & 3,710 & 0,148 & 99,36 \\
\hline \multicolumn{6}{c}{} &
\end{tabular}

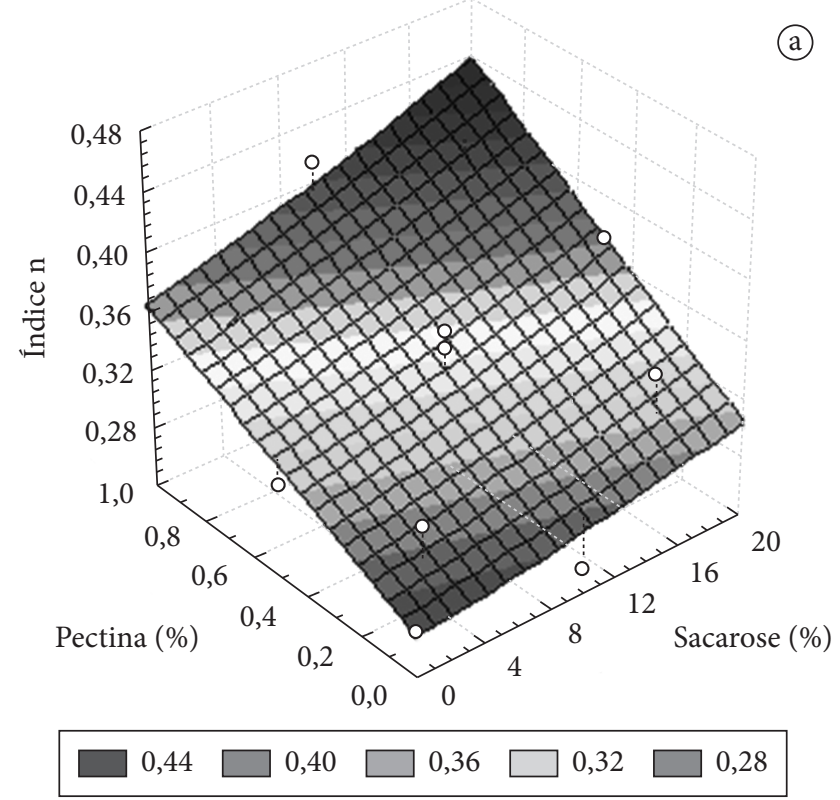

congelada, que diminui com o tempo e com a diminuição da temperatura.

Segundo Colla, Prentice-Hernandez (2003), as diferenças nas taxas de descongelamento podem ser explicadas com base em várias propriedades da água e do gelo, as quais são: elevado calor latente de cristalização; condutividade térmica (o gelo transmite energia calorífica a uma taxa quatro vezes maior do que a água); difusividade térmica (o gelo sofre uma mudança na temperatura a uma taxa aproximadamente nove vezes maior do que a água).

\subsection{Reologia}

Os reogramas das polpas de morango foram construídos a partir dos dados experimentais e foram feitos os ajustes não lineares pela Equação da Lei da Potência. Os valores de "n", "K" e os coeficientes de correlação $\left(\mathrm{R}^{2}\right)$ foram obtidos por este ajuste e estão apresentados na Tabela 4 para os sistemas antes do congelamento.

A Figura 17 mostra as superfícies de resposta para os índices " $n$ " (índice de comportamento de fluxo) e "K" (índice de consistência) em função das concentrações de sacarose e pectina para os sistemas depois do descongelamento.

O resumo da análise de regressão do índice de comportamento de fluxo (n) das polpas de morangos com adição de sacarose e pectina, antes do congelamento (AC) e depois do descongelamento (DC) está mostrado na Tabela 5.

Para a polpa de morango houve significância na interação dos fatores (sacarose e pectina) nas amostras antes do congelamento e depois do descongelamento em relação a " $n$ ". As inclinações das curvas de escoamento diminuem

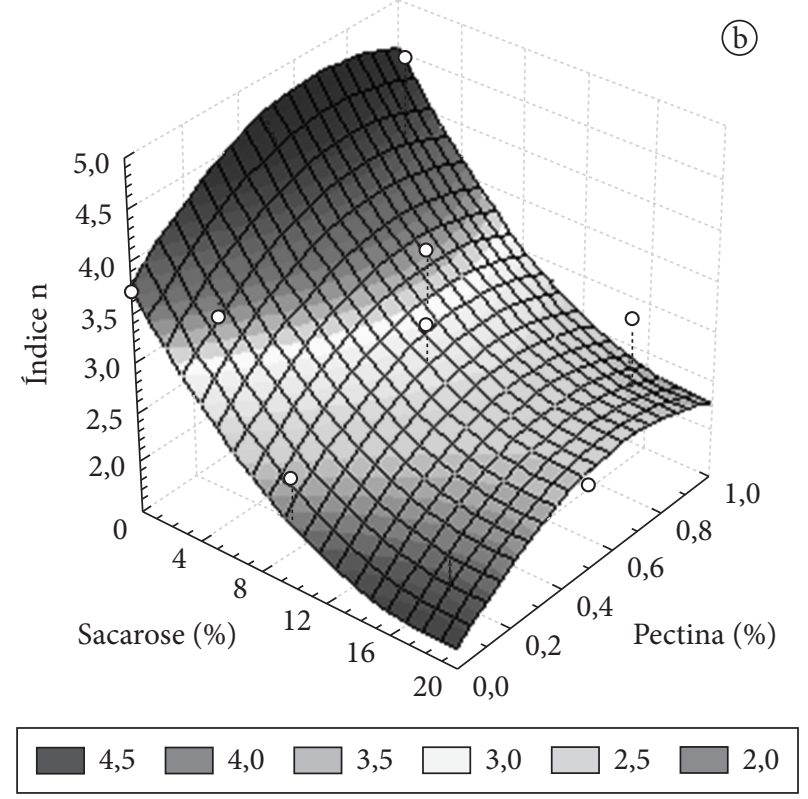

Figura 17. Superfícies de resposta para os parâmetros do modelo Ostwald-de-Waelle para sistemas de polpas de morango com aditivos em função das concentrações de sacarose e pectina. (a) índice de comportamento de fluxo $(n)\left(R^{2}=0,8355\right)$; (b) índice de consistência $(K)\left(R^{2}=0,7791\right)$. 
Tabela 5. Análise de regressão do índice de comportamento do fluxo das polpas de morango com adição de sacarose e pectina, antes do congelamento (AC) e depois do descongelamento (DD)

\begin{tabular}{clccc}
\hline Resposta & Fonte de variação & Estimativa & Erro padrão & Valor p \\
\hline & Intercepto & 0,243117 & 0,043742 & 0,003 \\
& Sacarose & 0,013816 & 0,005921 & 0,067 \\
“n” & Pectina & 0,395199 & 0,115472 & $0,019^{*}$ \\
AC & Sacarose^2 & $-0,000324$ & 0,00023 & 0,207 \\
& Pectina^2 $^{\wedge}$ & $-0,217894$ & 0,091657 & 0,063 \\
& Sacarosepectina & $-0,21861$ & 0,006049 & $0,015^{*}$ \\
& Intercepto & 0,279866 & 0,041566 & 0,001 \\
\hline \multirow{4}{*}{ “n” } & Sacarose & 0,007556 & 0,005626 & 0,237 \\
DD & Pectina & 0,248039 & 0,109727 & 0,073 \\
& Sacarose^2 & $-0,000111$ & 0,000212 & 0,323 \\
& Pectina^2 & $-0,142369$ & 0,087097 & 0,163 \\
& Sacarose $^{\star}$ pectina & $-0,018397$ & 0,005748 & $0,024^{\star}$ \\
\hline
\end{tabular}

* significativo, pelo teste $\mathrm{t}$, a $5 \%$ de probabilidade.

com o aumento da taxa de deformação, evidenciando assim decréscimo da viscosidade aparente com o aumento da taxa de deformação. Este comportamento é típico de polpas de frutas, como observado por Gasparetto, Guimarães (2000). Este comportamento foi encontrado também por Ferreira et al. (2002) em polpa de goiaba e por Cabral; Queiroz e Figueiredo (2002) em polpa de cupuaçu.

As Figuras 18 e 19 mostram as propriedades reológicas das polpas de morango com adição de pectina $0,5 \%$ e diferentes concentrações de sacarose antes e depois do congelamento.

Observa-se na Tabelas 4, Figura 17 e nas Figuras 18 e 19 que o índice de comportamento de fluxo (n) foi inferior a 1 em todos os tratamentos, caracterizando desta forma um comportamento não newtoniano.

O índice de comportamento do fluxo (n) foi maior para tratamentos constituídos de polpa de morango com adição de altas concentrações de pectina e sacarose significando que as amostras com adição de sacarose e pectina apresentaram menor pseudoplasticidade tanto antes quanto depois do descongelamento devido ao maior valor de (n). Isto resulta do progressivo alinhamento das moléculas rígidas com a força de cisalhamento (FERREIRA; GUIMARÃES; MAIA, 2007).O índice de consistência $(\mathrm{K})$ foi maior para as amostras com menores concentrações de sacarose e maiores concentrações de pectina antes e após o congelamento (Figura 17).

A viscosidade aparente $(\eta)$ é maior para tratamentos com altas concentrações de pectina e sacarose, o que está relacionado com o grau de integração sinérgica entre a pectina e a polpa de fruta, sendo o efeito mais pronunciado para altas concentrações de pectina. Para estes fluidos, sem tensão residual, a viscosidade aparente diminui com o aumento da taxa de deformação e este tipo de comportamento é normalmente atribuído às substâncias de elevada massa molecular presentes na solução e/ou aos sólidos dispersos em uma fase fluida, os quais podem permanecer suspensos ou decantados, dependendo do tamanho das partículas e de sua concentração (RAO, 1977).

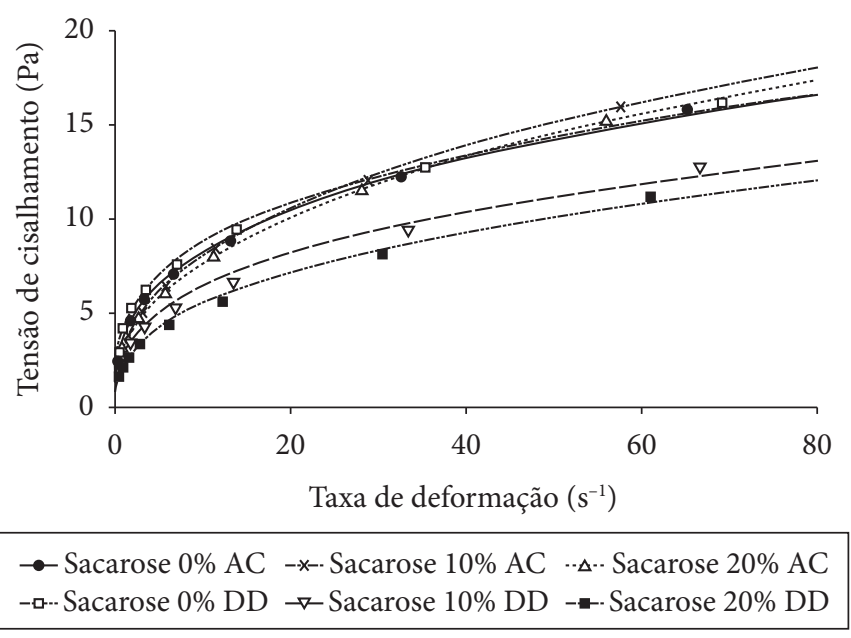

Figura 18. Reograma da polpa de morango com adição de $0,5 \%$ de pectina e várias concentrações de sacarose antes do congelamento (AC) e depois do descongelamento (DD) - relação entre tensão de cisalhamento e taxa de deformação.

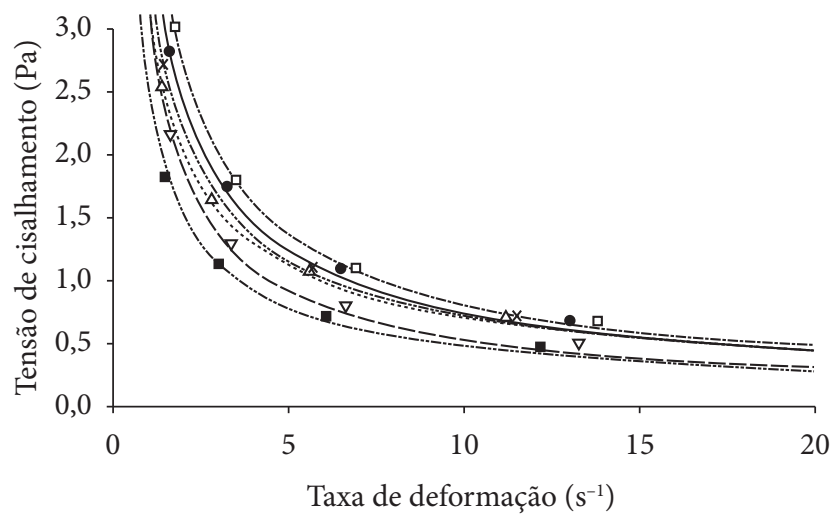

$\rightarrow-$ Sacarose 0\% AC $\quad$-x--Sacarose 10\% AC $\quad \cdot-\Delta-$ - Sacarose 20\% AC $\rightarrow-$ Sacarose 0\% DD $\rightarrow$-Sacarose 10\% DD $\rightarrow-$ Sacarose 20\% DD

Figura 19. Reograma da polpa de morango com adição de $0,5 \%$ de pectina e várias concentrações de sacarose antes do congelamento (AC) e depois do descongelamento (DD) - relação entre viscosidade aparente e taxa de deformação.

\subsection{Microestrutura, reologia e dinâmica do congelamento dos sistemas}

Em uma tentativa de correlacionar e verificar os efeitos do comportamento reológico dos sistemas de polpas de morango com adição de sacarose e pectina com a dinâmica e microestruturação dos cristais de gelo durante o congelamento, foram obtidas fotomicrografias em microcongelador e o desenvolvimento da frente de congelamento e a morfologia dos cristais foram analisados nestes sistemas.

A Figura 20 mostra fotomicrografias selecionadas em intervalos de tempo de 0, 2, 10 e 14 segundos após o início do congelamento de sistemas constituídos de polpas de morango com adição de $10 \%$ de sacarose e diferentes concentrações de pectina. 

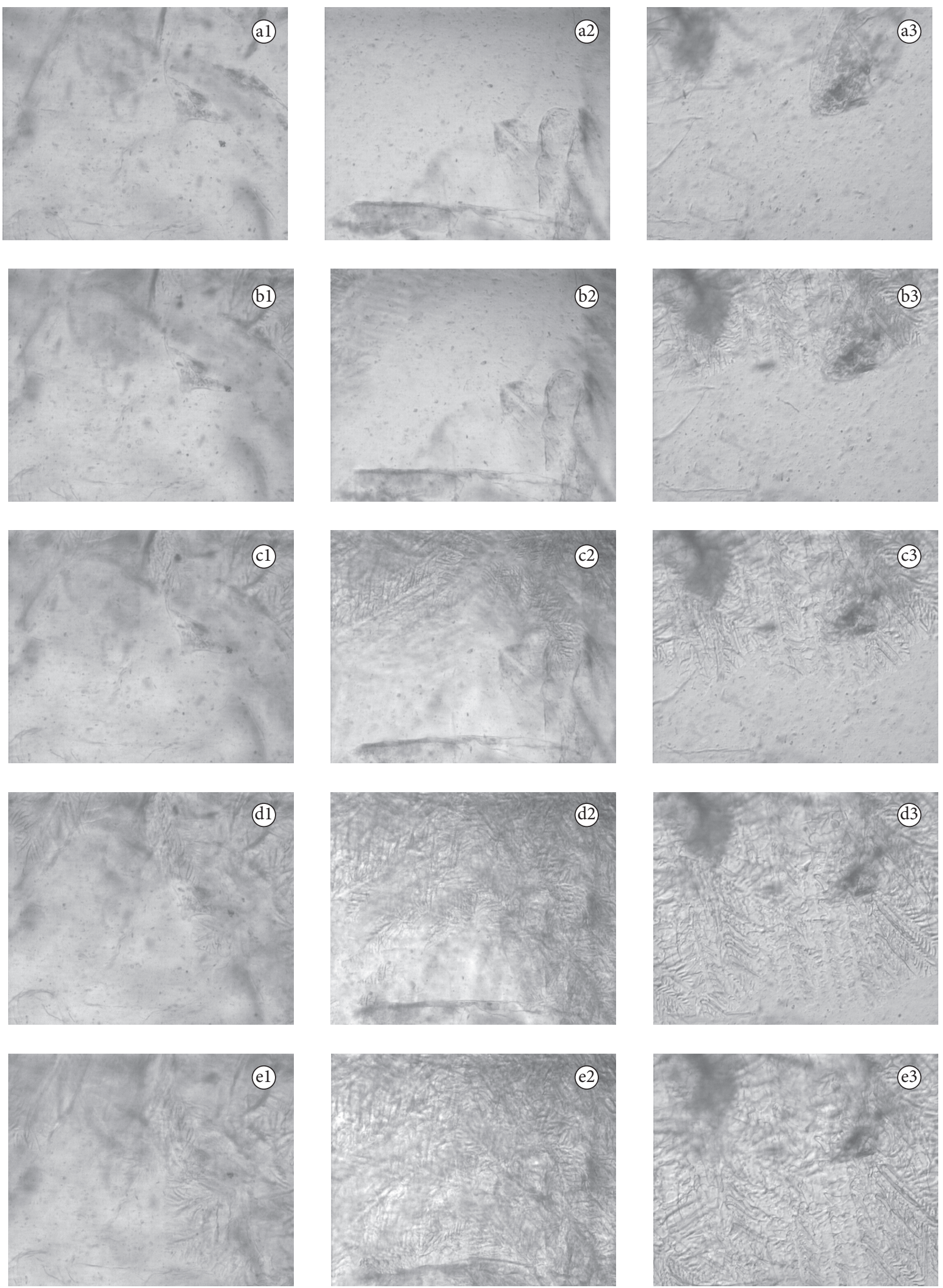

Figura 20. Fotomicrografias das polpas de morango com adição de $10 \%$ de sacarose e $0 \%$ (1), 0,5\% (2) e 1,0\% (3) de pectina nos tempos 0 (a), 2 (b), 6 (c), 10 (d) e 14 (e) segundos durante a cristalização. 
As fotomicrografias mostram que a estrutura, a morfologia e os espaçamentos entre os dendritos dos cristais de gelo na frente de congelamento apresentam-se semelhantes nos sistemas, indicando que a concentração de pectina não teve influência neste aspecto qualitativo em polpas de morango. Também se pode observar que no instante de 10 segundos após o início do congelamento, os sistemas constituídos de sacarose $10 \%$ com adição de pectina $0,5 \%$ e sacarose $10 \%$ com adição de pectina $1 \%$ se encontram praticamente congelados, enquanto nos sistemas sem adição de pectina este processo está apenas se iniciando.

Verifica-se também que, em sistemas com $0,5 \%$ de concentração de pectina, o avanço da frente de congelamento se dá com maior velocidade em relação aos demais sistemas. Estes resultados são compatíveis com aqueles obtidos nas estimativas, a partir da umidade inicial das amostras, das frações mássicas de gelo na coordenada central do cilindro, na qual os sistemas de polpas de morango constituídos de $10 \%$ de sacarose e $0,5 \%$ de pectina produziram maiores frações de gelo em função do tempo, conforme mostrado na Figura 11.

No substrato ácido da fruta, a pectina é um coloide que contém cargas negativas. A adição de açúcar a esse substrato influencia o equilíbrio entre a pectina e a água, desestabilizando a pectina, que forma uma malha semelhante a uma rede capaz de reter líquidos e aglutinar o açúcar sob a forma de um gel. A continuidade da malha formada pela pectina e a densidade das fibras dependem diretamente da concentração da pectina. Quanto maior a sua concentração, mais densas serão as fibras e, portanto, um gel mais forte. A rigidez da malha é também influenciada pela concentração de açúcar e pela acidez do meio. Quanto maior a concentração de açúcar, menor quantidade de água livre será encontrada na estrutura, logo a estrutura será mais rígida (SILVA, 2000).

\section{Conclusões}

As propriedades físico-químicas da atividade de água, $\mathrm{pH}$, acidez titulável e propriedades de cor não foram influenciadas pelo processo de congelamento nem pela adição de sacarose e pectina nas polpas de morango. A adição de sacarose e pectina aumentou o teor de sólidos solúveis e diminuiu o teor de umidade, não sendo influenciados pelo processo de congelamento/descongelamento para estas polpas.

Através dos históricos de temperatura e dos valores das frações mássicas de gelo, foi possível verificar que, durante a etapa de mudança de fase (tempo de 120 minutos), os sistemas constituídos de sacarose e pectina $0,5 \%$ apresentaram uma fração de gelo $20 \%$ maior quando comparados aos demais sistemas, indicando que nestes sistemas existe maior quantidade de água livre disponível para a formação do gelo.

Altas concentrações de sacarose e pectina foram responsáveis pela redução dos tempos de descongelamento em cerca de $20 \%$ quando comparados com os demais sistemas.

Altas concentrações de sacarose e pectina produziram os maiores índices de comportamento de fluxo, indicando que nestes sistemas existe uma menor pseudoplasticidade e que os sistemas com as menores concentrações de pectina e maiores concentrações de sacarose produziram os menores índices de consistência.

Estes resultados mostram que existem efeitos significativos da interação entre os fatores sacarose e pectina, comprovados também através das análises microestruturais em experimentos com microcongeladores.

Em termos do comportamento reológico, os resultados mostram que existe um efeito interativo entre os fatores sacarose e pectina sobre a viscosidade aparente dos sistemas que pode interferir na velocidade da frente de congelamento, indicando que possa existir uma combinação de concentrações sacarose e pectina ótima, em que a interação sinérgica entre os componentes da polpa, aditivos e condições de $\mathrm{pH}$ do meio disponibilize maior quantidade de água livre no meio favorecendo a mobilidade da frente de congelamento.

\section{Agradecimentos}

Ao CNPq (Conselho Nacional de Desenvolvimento Científico e Tecnológico) pelo apoio financeiro à pesquisa e à FAPEMIG (Fundação de Amparo a Pesquisa de Minas Gerais) pela concessão de bolsas.

\section{Referências bibliográficas}

ASSOCIATION OF OFFICIAL ANALYTICAL CHEMISTS - AOAC. Official methods of analysis. $15 \mathrm{ed}$. Arlington, 1990. $1298 \mathrm{p}$.

BRIGGS, J. L.; STEFFE, J. F. Using Brookfield data and the Mitschka method to evaluate Power Law foods. Journal of Texture Studies, v. 28, n. 5, p. 517-522, 1997.

BRUNINI, M. A.; DURIGAN, J. F.; OLIVEIRA, A. L. Avaliação das alterações em polpa de manga "Tommy-Atkins" congeladas. Revista Brasileira de Fruticultura, v. 24, n. 3, p. 651-653, 2002. Disponível em: <http://www.scielo.br/>. Acesso em: 23 maio 2006.

BUDIAMAN, E. R.; FENNEMA, O. Linear rate of water crystallization as influenced by temperature of hydrocolloid suspensions. Journal of Dairy Science, v. 70, n. 3, p. 535-46, 1987.

CABRAL, M. F. P.; QUEIROZ, A. J. M.; FIGUEIRÊDO, R. M. F. Comportamento reológico da polpa de cupuaçu (Theobroma grandiflorum Schum.) peneirada. Revista Brasileira de Produtos Agroindustriais, v. 4, n. 1, p. 37-40, 2002.

CARNEIRO, C. S. Estruturação de cristais de gelo e sua influência no dano celular. Lavras, 2001. 166 p. Tese (Doutorado) - Universidade Federal de Lavras - UFLA.

CHEVALIER, D.; LE BAIL, A.; GHOUL, M. Freezing and ice crystals formed in a cylindrical food model: part I. Freezing at atmospheric pressure. Journal of Food Engineering, v. 46, n. 4, p. 277-285, 2000.

CHITARRA, M. I. F.; CHITARRA, A. B. Pós-colheita de frutos e hortaliças: fisiologia e manuseio. 2 ed. Lavras: ESAL, 2005. 783 p.

COLLA, L. M.; PRENTICE-HERNÁNDEZ, C. Congelamento e descongelamento: a sua influência sobre alimentos. Vetor, v. 13, p. 53-66, 2003.

FENNEMA, O.; POWRIE, W. D.; MARTH, E. H. Low temperature preservations of foods and living. New York: Marcel Dekker, 1973.

FERNÁNDEZ, P. P. et al. Effects of locust bean, xanthan and guar gums on the ice crystals of a sucrose solution frozen at hight pressure. Food Hydrocolloids, v. 21, n. 4, p. 507-515, 2007. 
FERREIRA, G. M.; GUIMARÃES, M. J. O. C.; MAIA, M. C. A. Interações sinérgicas entre polpa de fruta e polissacarídeos em cisalhamento estacionário e dinâmico. In: ENCONTRO REGIONAL SUL DE CIÊNCIA E TECNOLOGIA DE ALIMENTOS, 9, 2007, Curitiba. Anais... Curitiba: Editora TecArt, 2007. p. 654-660.

FERREIRA, G. M. et al. Efeito da temperatura no comportamento reológico das polpas de caju e goiaba. Ciências Exatas e Naturais, v. 4, n. 2, p. 176-184, 2002.

GASPARETTO, C. A.; GUIMARÃES, D. H. P. Rheological behavior of pineapple and mango pulps: effect of the measuring systems. Revista de Ciência e Tecnologia, v. 8, n. 16, p. 91-96, 2000.

GEORGE, R. M. Freezing processes used in the food industry. Trends in Food Science \& Technology, v. 4, n. 5, p. 134-138, 1993.

HELDMAN, D. R. Handbook of food engineering. New York: Marcel Dekker, 1992. 756 p.

HOO, A. F.; MCLELLAN, M. R. The contributing effect of apple pectin on the freezing point depression of apple juices concentrates. Journal of Food Science, v. 52, n. 2, p. 373-375, 1987.

JIE, W.; LITE, L.; YANG, D. The correlation between freezing point and soluble solids of fruits. Journal of Food Engineering, v. 60, n. 4, p. 481-484, 2003.
MINOLTA COMPANY. Precise color communication: color control from feeling to instrumentation. New Jersey, 1994. 49 p.

MITSCHKA, P. Simple convertion of Brookfield R. V. T. readings into viscosity functions. Rheologica Acta, v. 21, n. 2, p. 207-209, 1982.

OTA, E. M. Influência das variáveis de processo de congelamento na qualidade final de pão tipo francês pré-assado. Campinas, 2006. 160 p. Dissertação (Mestrado em Engenharia de Alimentos) Universidade Estadual de Campinas - UNICAMP.

RAO, M. A. Rheology of liquid foods: a review. Journal of Texture Studies, v. 8, n. 2, p. 135-168, 1977.

RODRIGUES, M. I.; IEMMA, A. F. Planejamento de experimentos e otimização de processos. Campinas: Casa do Pão Editora, 2005. $326 \mathrm{p}$.

SILVA, J. A. Tópicos da tecnologia dos alimentos. São Paulo: Varela, 2000. $227 \mathrm{p}$.

WANG, C. C. H.; CHANG, K. C. Beet pulp and isolated pectin physicochemical properties as related to freezing. Journal of Food Science, v. 59, n. 6, p. 113-1154, 1994. 